FOR OFFICIAL USE

\title{
DESCRIPTIVE TEXT
}

\author{
AND \\ INDEX \\ FOR
}

CRPL-F PART B

\section{SOLAR - GEOPHYSICAL DATA}

ISSUED

NOVEMBER 1964

U. S. DEPARTMENT OF COMMERCE

NATIONAL BUREAU OF STANDARDS

CENTRAL RADIO PROPAGATION LABORATORY BOULDER, COLORADO 

TABLE OF CONTENTS

INTRODUCTION

I DAILY SOLAR INDICES

Relative Sunspot Numbers

Solar Flux Values, $2800 \mathrm{Mc} / \mathrm{s}$

Graph of Sunspot Cycle

I I SOLAR CENTERS OF ACTIVITY

Calcium Plage and Sunspot Regions

Mt. Wilson Magnetic Classifications of Sunspots

Coronal Line Emission Indices

Optical Observations

Solar X-ray Radiation

Ionospheric Effects

SWF

SCNA-SEA-burst

SFD

Riometer Absorption Events

IV SOLAR RADIO WAVES

$2800 \mathrm{Mc} / \mathrm{s}$ Observations $\quad 14$

$223 \mathrm{Mc} / \mathrm{s}$ Interferometric System 17

$169 \mathrm{Mc} / \mathrm{s}$ Interferometric Observations $\quad 17$

$108 \mathrm{Mc} / \mathrm{s}$ Observations 18

Spectral Observations - Ft. Davis 20

Spectral Observations - High Altitude Observatory 21

$\begin{array}{ll}9.1 \mathrm{~cm} \text { Spectroheliograms } & 22\end{array}$

$\begin{array}{llr}V & \text { COSMIC RAY INDICES } & 24\end{array}$

$\begin{array}{ll}\text { VI GEOMAGNETIC ACTIVITY INDICES } & 26\end{array}$

C, Kp, Ap and Selected Quiet and Disturbed Days 26

$\begin{array}{ll}\text { Chart of Kp by Solar Rotations } & 26\end{array}$

$\begin{array}{ll}\text { VII RADIO PROPAGATION QUALITY FIGURES } & 27\end{array}$

North Atlantic Radio Path 28

$\begin{array}{ll}\text { North Pacific Radio Path } & 29\end{array}$

Comparison Charts $\quad 30$

Useful Frequency Ranges 30

$\begin{array}{ll}\text { VIII ALERT PERIODS } & 30\end{array}$

$\begin{array}{ll}\text { Types of Alerts } & 30\end{array}$

IX INDEX FOR CRPL-F PART B 32

INTERNATIONAL YEARS OF QUIET SUN

GEOPHYSICAL CALENDAR FOR 1965 


\title{
SOLAR - GEOPHYSICAL DATA
}

\author{
INTRODUCTION
}

This pamphlet describes the data published in the monthly CRPL-F Part B report series* which are intended to keep research workers abreast of the major particulars of solar activity and the associated ionospheric, radio propagation and other geophysical effects. This report series is made possible through the cooperation of many observatories, 1aboratories and agencies as recorded in the detailed description of the tables and graphs which follow. The report is prepared in the Radio Warning Services Section, edited by Miss J. Virginia Lincoln assisted by Miss 0 . E. Youngdah1. These reports should not be considered as definitive publications because of the rapid publication schedule involved. Errata or revisions are included from time to time. Additions to the descriptive text will appear with the data when new material is added or revision is made.

Preliminary summaries of solar activity, prepared on a fast schedule, are issued Friday of each week from High Altitude Observatory in conjunction with CRPL and include solar activity through the preceding day. These are useful to groups needing information on the current status of activity associated with regions on the visible solar disk, but are not recommended for research uses unless such a prompt schedule of reporting is essential.

\section{DAILY SOLAR INDICES}

Relative Sunspot Numbers - The table includes (.1) the daily American relative sunspot numbers, $\mathrm{R}_{\mathrm{A}}$ as compiled by Sarah J. Hill, Wellesley College, Wellesley, Massachusetts, for the Solar Division of the American Association of Variable Star Observers, and (2) the provisional daily Zürich relative sunspot numbers, $R_{Z}$, as communicated by $M$. Waldmeier of the Swiss Federal Observatory. Because of the time required to collect and reduce the observations, $\mathrm{R}_{\mathrm{A}}{ }^{\prime}$ will appear one month later than $\mathrm{R}_{\mathrm{Z}}$.

The relative sunspot number is an index of the activity of the entire visible disk. It is determined each day without reference to preceding days. Each isolated cluster of sunspots is termed a sunspot group and it may consist of one or a large number of distinct spots whose size can range from 10 or more square degrees of the solar surface down to the limit of resolution (e.g. 1/8 square degree). The relative sunspot number is defined as $R=K(10 g+s)$, where $g$ is the number of sunspot groups and $s$ is 
the total number of distinct spots. The scale factor $\mathrm{K}$ (usually less than unity) depends on the observer and is intended to effect the conversion to the scale originated by Woif. The observations for sunspot numbers are made by a rather small group of extraordinarily faithful observers, many of them amateurs, each with many years of experience. The counts are made visually with small, suitably protected telescopes.

Final values of $R_{Z}$ appear in the IAU Quarterly Bulletin on Solar Activity, the Journal of Geophysical Research, these reports, and elsewhere. They usually differ slightly from the provisional values. The American numbers, $\mathrm{R}_{\mathrm{A}}{ }^{\prime}$, are not revised.

Solar Flux Values, $2800 \mathrm{Mc} / \mathrm{s}$-- The table also gives the combined daily level of emission from the solar disk and from any active regions present. The daily levels are determined on a frequency of $2800 \mathrm{Mc} / \mathrm{s}$ from observations made at the Algonquin Radio Observatory (ARO) of the National Research Council, Ottawa, Canada, with a reflector 1.8 meters diameter. Prior to 1962 these observations were made at Ottawa itself. The flux values are given in tabular form in units of $10-22 \mathrm{watts} / \mathrm{m}^{2} / \mathrm{c} / \mathrm{s}$, and commencing in 1964, have been determined from calibrations taken at 1400,1700 and $2000 \mathrm{UT}$. When the flux changes rapidly or there i.s burst activity in progress, the reported value is the best estimate of the undisturbed level for the local observing day. The flux values observed from day to day do not take into account the variations in the sun-earth distance due to the eccentric orbit of the earth. Although the observed radio values are suitable to use with observed ionospheric and other data, an adjustment must be introduced when these observations are used in studies of the absolute or intrinsic variations of solar radio flux. The table shows both the observed flux, S, and flux adjusted to I.A.U., $s_{A}$. No correction for atmosphere attenuation has been applied. It is believed that it is never below $1 \%$ in summer and rises to $2 \%$ in winter. These solar radio noise indices are being published in accordance wi.th a CCIR Recommendation from the Xth Plenary Assembly, Geneva 1963, which states "that the monthly-mean value of solar radio-noise flux at wavelengths near $10 \mathrm{~cm}$ should be adopted as the index to be used for predicting monthly median values of foE and foFl, for dates certainly up to 6 , and perhaps up to 12 months ahead of the date of the last observed value of solar radio-noise flux".

Graph of Sunspot Cycle -- The graph illustrates the recent trend of Cycle 19 of the 11-year sunspot cycle and some predictions of the future level of activity. As soon as sunspot minimum is confirmed -- probably it was August 1964 -- the graph will be changed to predictions for cycle 20 compared to the mean of cycles 8-19. The customary "12-month" smoothed index, $R$, is used throughout, the data being final $R_{Z}$ numbers except for the current year. Predictions shown are those made for one year after the latest available datum by the method of A. G. McNish and J. V. Lincoln (Trans. Am. Geophys. Union, 30, 673-685, 1949) modified by the use of regression coefficients and mean cycle values recomputed for Cycles 8 
through 18. Cycle 19 began April 1954, when the minimum $\overline{\mathbf{R}}$ of 3.4 was reached. Tabular values of the smoothed index, $R$, appear regularly in the CRPL-F Part A "Ionospheric Data" reports and CRPL "Ionospheric Predictions" series and are available upon request.

\section{SOLAR CENTERS OF ACTIVITY}

Calcium Plage and Sunspot Regions -- The table gives particulars of the centers of activity visible on the solar disk during, the preceding month. These are based on estimates made and reported on the day of observation and are therefore of limited reliability. The calcium plage region identifications, in particular, should be considered preliminary, subject to change after more detailed scrutiny.

The table gives the heliographic coordinates of each center (taken as the calcium plage unless two or more significantly and individually active sunspot groups are included in an extended plage) in terms of the Greenwich date of passage of the sun's central meridian (CMP) and the latitude: the serial number of the plage as assigned by McMathHulbert Observatory: the serial number of the center in the previous solar rotation, if it is a persisting region, or an otherwise appropriate statement: particulars of the plage at CMP: area, central intensity: a summary of the development of the plage during the current transit of the disk, where $\mathrm{b}=$ born on disk, $l=$ passed to or from invisible hemisphere, $\mathrm{d}=$ died on disk, and / = increasing, - = stable, 1 = decreasing: age in solar rotations: date first seen, month/day: and duration of plage on disk given in days: particulars of the associated sunspot group, if any, at CMP: area and spot count and the summary of development during the current disk transit, similar to the above. The unit of area is a millionth of the area of a solar hemisphere: the central intensity of the calcium plages is roughly estimated on a scale of $1=$ faint to $5=$ very bright. Parentheses indicate region was not observed on CMP date; values are those nearest CMP date.

Calcium plage data are available through the cooperation of the McMath-Hulbert Observatory of the University of Michigan. The sunspot data are compiled from reports from the U.S. Naval Observatory, Sacramento Peak Observatory and from reports from Europe, Asia and Japan received through the daily ursigram network.

Mount Wilson Magnetic Classifications of Sunspots -- This table lists the date and time (UT) of the observations, the approximate heliocentric coordinates, and the magnetic classification of the sunspot groups, as observed at the Mt. Wilson Observatory. Only those groups for which magnetic measures are available will be listed; no attempt will be made to number groups. 
The classification system gives the maximum magnetic information. The classifications are defined as follows:

$\alpha_{p} \quad$ All the magnetic measures in the group are of the same polarity which is that corresponding to the preceding spots in that hemisphere for that cycle.

$\alpha_{\mathrm{f}} \quad$ All the magnetic measures in the group are of the same polarity which is that corresponding to the following spots in that hemisphere for that cycle.

Bp A bipolar group in which the magnetic measures indicate that the preceding spots are dominant.

$\$$ A bipolar group in which the magnetic measures indicate a balance between the preceding and following spots.

Bf A bipolar group in which the magnetic measures indicate that the following spots are dominant.

By A group which has genera1 $\beta$ characteristics but in which one or more spots are out of place as far as the polarities are concerned.

$Y$ A group in which the polarities are completely mixed.

Coronal Line Emission Indices -- Emission intensity indices for the green (Fe XIV at $\lambda$ 5303) and red (Fe X at $\lambda 6374$ ) coronal lines are summarized in the table entitled Provisional Coronal Line Emission Indices. The indices are based on measurements made at $5^{\circ}$ intervals around the periphery of the solar disk by the High Altitude Observatory at Climax, Colorado, and by Harvard University observers at Sacramento Peak (the USAF Sacramento Peak Observatory at Sunspot, New Mexico, under contract $\mathrm{AF}$ 19(604)-146). The measurements are expressed as the number of millionths of an Angstrom of the continuum of the center of the solar disk (at the same wavelength as the line) that would contain the same energy as the observed coronal line. The indices have the following meanings:

$$
\begin{aligned}
\mathrm{G}_{6}= & \text { mean of } \mathrm{six} \text { highest line intensities in quadrant } \\
& \text { for } \lambda 5303 . \\
\mathrm{R}_{6}= & \text { same for } \lambda 6374 . \\
\mathrm{G}_{1}= & \text { highest value of intensity in quadrant } \\
& \text { for } \lambda 5303 . \\
\mathrm{R}_{1}= & \text { same for } \lambda 6374 .
\end{aligned}
$$


The dates given in the table correspond to the approximate time of CMP of the longitude zone represented by the indices. The actual observations were made for the northeast and southeast quadrants 7 days before; for the southwest and northwest quadrants 7 days after the CMP date given.

Once every three months Final Coronal Line Emission Indices are printed. These tables contain data from Pic du Midi and Kislovodsk as we 11 as Sacramento Peak and Climax. The indices are computed in the same manner as for the provisional table.

Notes: 1. From calibrations in February - March 1960 it was determined that all intensities from the Climax and Sacramento Peak Observatories during the years 1956-1959, inclusive, if multiplied by the factor 0.60 , will be expressed in millionths of equivalent Angstroms to a somewhat lower precision. Intensities prior to 1956 cannot be compared precisely with those obtained later because of changes in observing and reduction techniques. They may be converted roughly to millionths of equivalent Angstroms by the use of the table given by Billings and Varsavsky, 1955, Zs.f Ap. 38, 160. In F185B several corrections were made to October and November 1959 coronal line emission indices published in $\mathrm{F} 183 \mathrm{~B}$ and $\mathrm{F} 184 \mathrm{~B}$, respectively.

2. The October 1962 through March 1963 final coronal line emission indices were revised and the correct data appear in CRPL-F 226, issued June 1963.

To obtain rough measures of the integrated emission of the entire solar disk in either of the lines, assuming the coronal changes to be small in a half solar rotation, it is satisfactory to perform the following type of summation given in example for 15 October:

$$
\left(\begin{array}{l}
\text { MEAN DISK EMISSION } \\
\text { IN } 5303
\end{array}\right)_{15 O C T}=\frac{1}{N}\left[\sum_{15 O C T}^{22 \text { OCT }}\left\{\left(G_{6}\right)_{N E}+\left(G_{6}\right)_{S E}\right\}+\sum_{8 O C T}^{14 O C T}\left\{\left(G_{6}\right)_{S W}+\left(G_{6}\right)_{N W}\right\}\right]
$$

where $\mathrm{N}$ is the number of indices entering the summation.

Such integrated disk indices as well as integrated whole-sun indices are computed for each day and are published by the High Altitude Observatory at Boulder, Colorado.

\section{SOLAR FLARES}

Optical Observations -- The table presents the preliminary record of solar flares as reported to the CRPL on a rapid schedule at the sacrifice of detailed accuracy. Definitive data are published later in the IAU 
Quarterly Bulletin on Solar Activity, in various observatory publications and elsewhere. The present listing serves to identify and describe the phenomena observed without time to verify questionable values.

Reporting directly to the CRPL are the following observatories: Haleakala (Maui, Hawaii), Huancayo Geophysical Institute, Lockheed, McMath-Hulbert, Sacramento Peak, Swedish Astrophysical Station on Capri, C.S.I.R.O. Sydney, Manila Observatory, and Wendelstein. The remainder report through the Ursigram centers or are available through the IGY Wor 1d Data Center-A for Solar Activity, High Altitude Observatory, Boulder, Colorado. Observations are made in the light of the center of the H-alpha line unless noted otherwise. The reports from Sacramento Peak, New Mexico (communicated to CRPL by the High Altitude Observatory at Boulder), are from observations at the USAF Sacramento Peak Observatory at Sunspot, New Mexico, by Harvard University observers, under contract AF 19 (604)-4961.

A National Science Foundation grant supports the flare patrol program at the McMath-Hulbert Observatory and at Haleakala, Maui. National Aeronautics and Space Administration funds assist the Huancayo Geophysical Institute, Lockheed, and C.S.I.R.O. Sydney flare patrols.

For each flare or subflare are listed the reporting observatory using IAU Quarterly Bulletin on Solar Activity designations; the date; beginning and ending times; time of maximum phase; the heliographic coordinates in degrees; McMath serial number of the region; duration (flares only), the flare importance on the IAU scale of 1- to 3+; nature and completeness of available observations where $\mathrm{C}=$ a complete, or quasi complete, sequence of photographs was obtained, $P=$ one or a few photographs of the event were obtained resulting in incomplete time coverage, $V=$ all (or most of) the development of the flare was visually observed, or $S=$ flare was seen visually for a small part of its probable duration, or observing conditions where 1 means poor, 2 fair and 3 good; time of measurement for tabulated width of $H \alpha$ or tabulated area; measured (i.e. projected) maximum area in square degrees; corrected maximum area in square degrees (which equals measured area times secant $h$ where $h$ is the heliocentric angle); maximum effective line-width in $H \alpha$ expressed in percent of the continuous spectrum, and remarks in the IAU system of notes where $a=$ eruptive prominence for which the base has a heliocentric distance of at least $90^{\circ}, \mathrm{b}=$ probably the end of a more important flare, $c=$ invisible 10 minutes before, $d=$ brilliant point, $e=$ two or more brilliant points, $f=$ several eruptive centers, $g=$ no spots visible in the neighborhood, $h=$ the flare is accompanied by a dark filament (surge) of high sightline velocity, $i$ = very extensive active region, $j=$ marked variations in the intensity of the plage area, also before and (or) after the real flare event, $k=$ several intensity maxima, 1 = filaments already existing in the neighborhood show effects of sudden activation, $m=$ the flare has a strong continuous spectrum (is visible in white light), $\mathrm{n}=$ the continuous spectrum shows effects of polarization, $0=$ the observations have been made in the calcium II lines $H$ or $K, p=$ the flare shows helium $D_{3}$ in emission, $q$ = the flare shows the Balmer continunm in emission, and $r=$ the $H \alpha$ line shows a marked asymetry suggesting outgoing matter of high velocity. The following 
symbols are used in the table:

$$
\begin{array}{cr}
D=\text { Greater than } & U=\text { Approximate } \\
E=\text { Less than } & \square=\text { Not reported } \\
\text { (In older lists } \varepsilon=\text { Plus) }
\end{array}
$$

A final column lists provisionally the occurrence of simultaneous ionospheric effects as observed on selected field-strength recordings of distant high-frequency radio transmissions: a more nearly definitive list of these ionospheric effects, including particulars, appears in these reports after the lapse of a month (see below). All times are Universal Time (UT or GCT). Beginning with January 1962 data the times of no patrols for flare observations, from the observatories whose data are published in the table and which give such information, are inserted in chronological order with the flare data. Because some observatories report flares, but not the periods covered by their observations, flares may be included in the table during hours of reported no patrol. A graph also presents these intervals for which there were no patrols for flare observations for the observatories indicated in the footnote.

Notes: 1. All the flare data are recorded on IMB punched cards. As errata are received the punched cards are corrected. These errata are not always published in these reports. Copies of the cards or tabulations from them are available at cost through the IGY World Data Center A for Ionosphere and Airglow, CRPL, National Bureau of. Standards, Boulder, Colorado, U.S.A.

2. Major errors have occurred in the area listing in these reports for the Russian flares until 1960 data. We at NBS misunderstood some of the original entries. The Simeiz flares in F156B for example, were for June 1957, not July 1957. Revised flare 1ists, as we11, have been received for IGY-IGC flares from the following observatories: Abastumani, Alma-Ata, Moscow Gaish, Kiev University, Pirculi, Simeiz, Tashkent, and Voroshilov and are available as described above.

3. The flare position reports from Hawaii have been corrected from July 1, 1957 to December 10, 1960. Flare coordinates reported since December 10, 1960 have been computed correctly. The measured and corrected areas for flares from Hawail as published for July 1957 through November 1959 should be divided by two to make the entries correct.

4. The flares incorrectly labelled "Boulder" in F178B and $F 179 B$ are those for Greenwich Royal Observatory, Herstmonceux. As stated above the corrected data are available on IBM punched cards. 
5. Beginning October 1, 1960 the following U.S. observatories: Climax, Haleakala (formerly called Hawaii when patrol at Makapuu Point, Oahu), Lockheed and Sacramento Peak, are reporting maximum area in square degrees corrected according to a method proposed by C. S. Warwick of the National Bureau of Standards. As of August 1964 the Huancayo, Peru Geophysical Institute is also using the same method. These observatories are now basing their flare importances on this corrected area in accordance with IAU rules. Previously they had based their importances on the measured areas. The formula being used is:

$$
\text { Corrected area }=\frac{\text { measured area }}{\cos \phi+0.2 \sin \varphi} \text { where } \phi \text { is the }
$$

central distance. This factor represents the variation in apparent area that depends only on central distance, and avoids an infinity at the limb. Graph was published in CRPL-F 197 Part B, January 1961 and is repeated below:

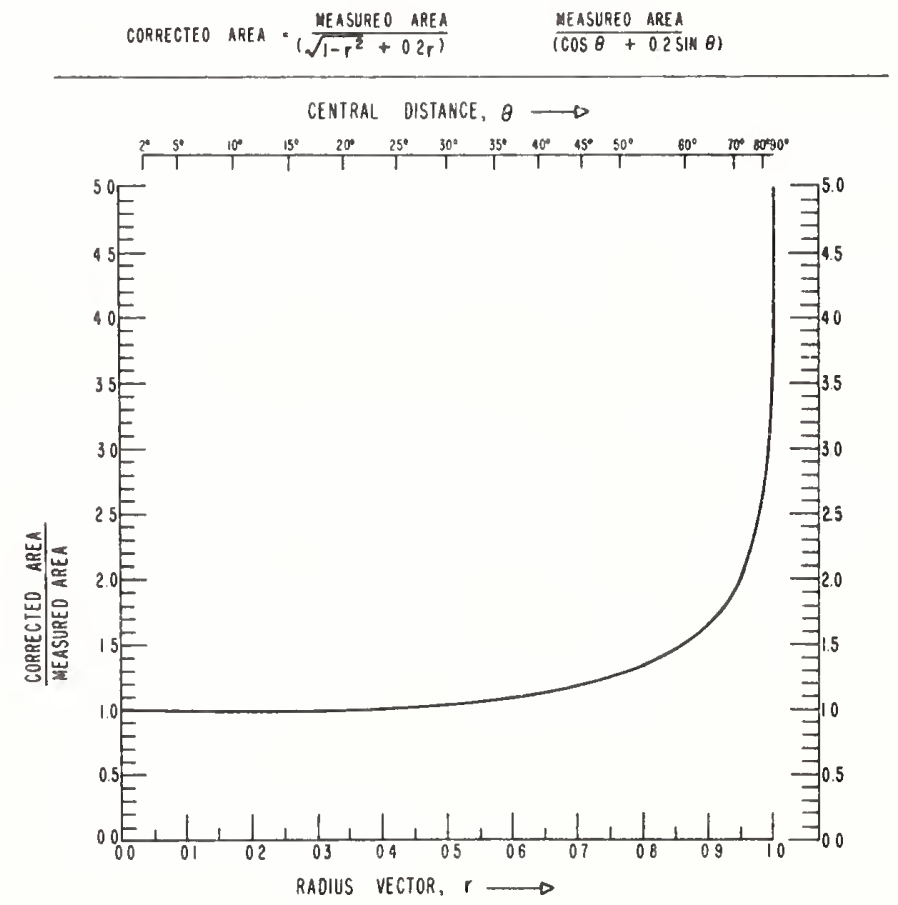

Solar X-ray radiation -- The NRL X-Ray Monitoring Satellite has provided numerous measurements of solar-x-ray emissions during 1964. The data published consist of tables of observing times and daily averages of the solar x-ray flux. Outstanding events are also listed. This program is under the direction of Robert $W$. Kreplin of the U. S. Naval Research Labora* tory. 
Instrumentation for the experiment consisted of five photometers sensitive in different but overlapping regions of the soft $x$-ray spectrum. These photometers are gas filled ionization chambers whose wavelength sensitivity is determined by the window material and the gas filling. Initially the bands covered included 2-8 A, 8-14 A, 8-16 A, 44-55 A and 44-60A. Failure of the 8-16 and 44-55 A photometer about one month after launch reduced the number of bands monitored but did not seriously effect the wavelength coverage of the experiment. Reference (3) describes the experiment in some detail giving the actual wavelength response curves of the photometers, as well as a discussion of preliminary results.

The column entries in the table following the date are explained below.

1. Times of Observation

These are the intervals of time (UT) when the satellite was in range of a telemetry station. Intervals have not been included when $x-r a y$ flux could not be reduced from the records due to noise or other interference.

\section{Average X-ray Flux}

a. $44-60 \mathrm{~A}$

The average flux is calculated from the records reduced for the listed intervals. This reduction is made assuming that the solar $x$-ray spectrum $c$ an be approximated by a $0.5 \times 10^{6} 0_{\mathrm{K}}$ "gray body" (ref. 1). This assumption is used on 1y for convenience. Austin, Purce11, and Tousey (ref. 2) have photographed a line spectrum in the region 44-60 A. Calculation of the flux values using this spectrum does not yield a value greatly different from that calculated here. The probable limit of error in each flux value is approximate $1 y \pm 10 \%$.

b. $\underline{8-12 A}$

The 8-12 A flux is calculated on the assumption that this region of the spectrum may be approximated by a $2 \times 10^{6}{ }^{\circ} \mathrm{K}$ "gray" body. Earlier published results have given the flux in band 8-20 A. Measurement of the solar spectrum between 13 and 26 Angstroms by Blake (to be published) has revealed a number of emission lines. Therefore, it seems advisable to limit the calculation to the region of sensitivity of the photometer (ref. 3).

Normally the 8-12 A flux is below the threshold of the measurement system. The numbers listed in this column preceded by < indicate the nominal threshold value for the day. 
c. $\underline{0-8} \mathrm{~A}$

The flux in this spectral range is calculated using a $2 \times 10^{6}$ oK "gray" body assumption. Here also the flux is normally below the threshold of the measurement system and the column entry represents the threshold value.

Al1 flux values are in ergs $\mathrm{cm}^{-2} \mathrm{sec}^{-1}$. The probable limit of error for the 8-12 and 0-8 A measurements are $\pm 10 \%$ for purposes of comparison.

3. Outstanding Events

In this table are listed those intervals in which the $\mathrm{x}$-ray flux was significantly greater than the average for the day.

$* * * * * *$

\section{REFERENCES}

1. Kreplin, R. W., Solar X-rays, Ann. Geophys. 17, $151-161,1961$.

2. Austin, W. E., J. D. Purce 11 and R. Tousey, Astron. J. 69, 133,1964 .

3. Kreplin, R. W., NRL Solar Radiation Monitoring Satellite, Description of Instrumentation and Preliminary Results, Presented at the COSPAR Symposium (Working Group 2) at Florence, Italy, 11 May 1964, to be published in SPACE Research V.

Ionospheric Effects - SID, sudden ionospheric disturbances (and GID gradual ionospheric disturbances) may be detected in a number of ways: shortwave fadeouts (SWF), increases in cosmic absorption (SCNA), enhancement of low frequency atmospherics (SEA), sudden phase anomalies at VIF (SPA), sudden enhancements at VIJF (SES) and sudden frequency deviations (SFD).

A table lists these phenomena jointly giving: date; beginning, ending and maximum phase in UT; type and importance rating if SWF; percent absorption and importance if SCNA; importance if SEA; or degrees of phase change if SPA with path designated; importance if SES; cycle per second frequency deviation if SFD and frequencies on which observed; importance of solar noise burst observed at $18 \mathrm{Mc} / \mathrm{s}$; a geographically widespread index for type of event; station observing event; and associated solar flare, if known.

SWF

The SWF events are listed in first columns and have been recognized on field-strength recordings of distant high-frequency radio transmissions. Under a coordinated program, the staffs at the following ionospheric sounding 
stations contribute reports that are screened and synthesized at CRPLBoulder: Ft. Belvoir, Va., Boulder, Colo. and Anchorage, Alaska (CRPL Stations: $\mathrm{BE}, \mathrm{BO}, \mathrm{AN})$; Huancayo, Peru and University of West Indies, Trinidad; (CRPL-Associated Stations: HU, TR); Ft. Monmouth, N.J., White Sands, N. Mex., Adak, Alaska, and Okinawa (U.S. Signal Corps Stations: FM, WS, $A D, O K)$. MCMath-Hulbert Observatory (MC) and Hiraiso Radio Wave Observatory, Japan (TO) also contribute such reports. In addition, reports are volunteered by Cable and Wireless (CWt $=$ Hong Kong, $\mathrm{CWH}=$ Singapore, CWH+ = Accra, $\mathrm{CW}^{*}=$ Barbadoes, CW** = Somerton, England, CW*r** = Brentwood, England); Netherlands Postal and Telecommunications Spervices at NERA (NE) and Paramaribo (PA); Swedish Telecommunications, Enkoping, Sweden (SW); New Zealand Post and Telegraph Department (NZ) and others: these usually specify times of SWF and the radio paths involved. Through the Ursigrams, reports are available from still other stations: such as Breisach, GFR (BR), Canberra, Australia (CA), Darmstadt, GFR (DA), Juhlesruh, GDR (JU), Kuhlungsborn, GDR (KU), Lindau, GFR (LI), Predigstuh1, GFR, (PS), Prague, Czechos lovakia (PU).

In the coordinated program, the abnormal fades of field strength not obviously ascribable to other causes, are described as short-wave fadeouts with the following further classification:

\author{
S-SWF (S): sudder drop-out and gradual recovery \\ Slow S-SWF (SL): drop-out taking 5 to 15 minutes and gradual \\ recovery \\ G-SWF (G): gradual. disturbance: fade irregular in \\ either drop-out or recovery or both.
}

When there is agreement among the various reporting stations on the time (UT) of an event, it is accepted as a widespread phenomenon and listed in the table.

The degree of confidence in identifying the event, a subjective estimate, is reported by the stations and this is summarized in an index of certainty that the event is geographically widespread, ranging from 1 (possible - single station) to 5 (definite - many stations). The times given in the table for the event are from the report of a station (listed first in the group of stations) that identified it with high confidence. The criteria for the subjective importance rating assigned by such station on a scale of 1- to 3t include amplitude of the fade, duration of event and confidence of reality of event. The published summary importance rating is also subjective with greater consideration given to reports on paths near the subsolar point for the particular event.

Note: The table of SID observed at Washington included in CRPL F-reports prior to F-135 were restricted to events classed here as S-SWF.

SCNA-SEA-bursts

Sudden ionospheric disturbances are next listed in the table which have been recognized on recorders for detecting cosmic absorption at about $18 \mathrm{Mc} / \mathrm{s}$ 
(SCNA) or on recorders for detecting enhancements of low frequency atmospherics at about $27 \mathrm{kc} / \mathrm{s}$ (SEA). Solar radio bursts at $18 \mathrm{Mc} / \mathrm{s}$ are identified on the SCNA records are also given in the table.

Reports are received either directly or through the IGY Wor 1d Data Center-A for Solar Activity at the High Altitude Observatory, Boulder, Colo. The following observatories report SCNA: McMath-Hulbert Observatory (MC); High Altitude Observatory, Boulder, Colo. (BO); University of Hawaii, Haleakala, Maui, Hawaii (HA); Manila Observatory (MA) and Osservatorio Astronomico su Monte Mario, Rome, Italy (RO). These five stations also report solar noise bursts observed at $18 \mathrm{Mc} / \mathrm{s}$. The SEA reports come from the following: Dunsink Observatory, Ireland (DU); Observatorio del Ebro, Tortosa, Spain (TR); Research Institute of Atmospherics, Toyokawa, Japan (TY); two stations operated by the Netherlands PTT at Nederhorst den Berg, Netherlands (NE), and Paramaribo, Dutch West Indies (PA); Panska Ves Observatory near Prague, Czech. (PU); High Altitude Observatory, Boulder, Colo. (BO); McMath Hulbert Observatory (MC); University of Hawaii (HA); Manila Observatory (MA) Osservatorio Astronomico su Monte Mario, Rome, Italy (RO); Willard Ha1I, Preston, England (LO); Neustrelitz, GDR, (NU); Kuhlungsborn, GDR, (KU); a group of American Association of Variable Star Observers located at Brooklyn, N.Y. (A1), Paterson, N.J. (A3), Ramsey, N.J. (A5), Oshkosh, Wis. (A6), Blauvelt, N.Y. (A10), Beverley Hil1s, Calif., (A14) Vermont (A15) and Sao Paulo, Brazil (A16) and an amateur astronomer in Hobart, Tasmania (TA).

These reports are coordinated at CRPL-Boulder. When there is agreement among the various reporting stations on the time (UT) of an event, it is accepted as a widespread phenomenon and listed in the table. Some phenomena are listed, if noted at only one location, if there has been a flare or another type of flare-associated effect reported for that time.

In the table under the type of event the subjective importance of the event is given on a scale of 1 minus to 3 plus. Next there is the index of geographic widespread certainty ranging from 1 (possible) to 5 (definite). The times of beginning, end and maximum phase of the event in UT are given as reported by the station listed first in the group of observing stations. If the event is an SCNA, a percent absorption figure is given. This absorption is calculated by the formula:

$$
\text { SCNA } \%=\frac{I_{n}-I_{f} \times 100}{I_{n}}
$$

where $I_{n}=$ noise diode current required to give a recorder deflection equal to that which would have occurred in the absence of a flare, i.e. a value extrapolated from cosmic noise level trend before and after a flare. The previous day's record may be considered if necessary.

and $I_{f}=$ noise diode current required to give a recorder deflection equal to the level at the time of maximum absorption. 
$\underline{S P A}$

Sudden phase anomalies (SPA) are observed as a phase advance of the downcoming skywave on VLF recordings. An estimate of the intensity can be obtained in terms of the degree of phase shift (see Chilton, C.J. et al, Jour. Geophys. Res. 68, 5421-5436, October 1, 1963). The length of path and amount of sunlight on the path must of course be considered.

Reports are received from the National Bureau of Standards, Boulder, Colo. (BO) recording regularly Rugby, England (GBR $16 \mathrm{kc} / \mathrm{s}$ ), Balboa, Canal Zone (NBA $18 \mathrm{kc} / \mathrm{s}$ ) and Maui, Hawaii, U.S.A. (NPM $19.8 \mathrm{kc} / \mathrm{s}$ ) and recording irregularly Jim Creek, Wash., U.S.A. (NPG $18.6 \mathrm{kc} / \mathrm{s}$ ), Annapolis, Md., U.S.A. (NSS $22.3 \mathrm{kc} / \mathrm{s}$ ), Cutler, Maine, U.S.A. (NAA $14.7 \mathrm{kc} / \mathrm{s}$ ) and ottawa, Canada (CYZ $40.80 \mathrm{kc} / \mathrm{s}$ ). Other reports are from NBS Maui, Hawaii, U.S.A. (MU) recording NBA, from Battelle Instltute, Frankfurt, G.F.R. (FR) recording NBA and GBR., and from Tucuman, Argentina (TU) recording NBA and WWVL.

The CRPL High Latitude Space Environment Monitoring Station at Anchorage, Alaska beginning in January 1965 will be recording GBR, NBA and NPM.

In the table under SPA column the degrees of phase change are given for the path reporting maxirum phase change while under the station colum the parenthetical remark gives the call letters with the degrees of phase change for each transmitter recorded at the observing station. For each event the time of beginning, time of maximum phase advance, and time of ending in UT are given.

\section{SES}

Sudden enhancements of signal strength (SES) are observed on field strength recordings of extreme $1 \mathrm{y}$ stable VLF transmissions. The times of beginning, ending and maximum are given in UT, as well as a subjective importance rating from 1 - to $3+$ as in the column headed SES and a widespread index as described under SWF above. The reporting stations are the AAVSO observers $\mathrm{A} 1, \mathrm{~A} 3, \mathrm{~A} 5$, and $\mathrm{A}] \mathrm{4}$.

\section{$\underline{\text { SFD }}$}

An SFD, sudden frequency deviation, is defined as a rapid change in the received frequency of an ionospherically propagated signal observed during a solar flare. SFD's are detected by comparing the signal received from a highly stable transmitter with a locally generated signal of comparable stability which is offset from the transmitted frequency by a few cycles per second. This produces a frequency difference of a few cycles per second, and any sudden changes in the phase path of the ionospherically propagated signal are indicated by rapid changes in this difference frequency. A typical SFD consists of a rapid positive frequency shift followed by a negative shift and a gradual return to the pre-flare conditions. However, there is great variation observed from one event to another. The maximum positive frequency deviation observed varies with the operating frequency and the path length involved. SFD's as small as a tenth of a cycle per second and as large as forty cycles per second have been observed. A more complete discussion of this technique and the related theory, and additional references, can be found in "Doppler Studies of the Ionospheric Effects of 
Solar Flares" by K. Davies (Preceedings of the International Conference on the Ionosphere, London, July 1962, Institute of Physics and the Physical Society, London, 1963).

The times of the beginning, end, and maximum phase, all in UT, and the maximum positive frequency deviation (in cycles per second) are reported for SFD events. In the station column the receiving location is given, such as National Bureau of Standards, Boulder, Colo., U.S.A. (BO) with the parenthetical remark giving the transmitting station call letters and transmitted frequency to nearest $\mathrm{Mc} / \mathrm{s}$ together with the frequency deviation in cycles per second. Other receiving stations are Accra, Ghana (AC), Natal, Brazil (NA), U.S.A. (HA) and Battelle Institute, Frankfurt, G.F.R. (FR).

For each event a flare beginning time, if known, that may be associated with the SFD, is given the final column of the table. An asterisk indicates that at the time of publication there was no known flare patrol at the time of the SFD.

\section{Riometer Absorption Events}

The table shows the periods of absorption seen on a riometer at South Pole. The riometer is operated by the Central Radio Propagation Laboratory of the National Bureau of Standards, with financial support from the National Science Foundation. The equipment operates at $26 \mathrm{Mc} / \mathrm{s}$ and uses a zenithal antenna of beamidth $\pm 30^{\circ}$ to the half-power points.

The columns show date, time of start of event, time of maximum absorption, time of end of event, absorption in tenths of a decibel at the maximum, number of major absorption peaks in the event (i.e., those exceeding half the largest). All dates and times are in U.T. The report is confined to those events having at least $0.3 \mathrm{db}$ of absorption at the maximum. Groups of short events separated by less than two hours are normally reported as a single event.

\section{SOLAR RADIO WAVES}

$2800 \mathrm{Mc} / \mathrm{s}$ Solar Noise Observations -- Burst phenomena are measured above the quiet sun level on the basis of the classification described by Covington, Jour. Astro. Soc. Can. 45, 1951, and Paper 28, Paris Symposium on Radio Astronomy, 1959. These terms have also been found to be of significance over large bands in the microwave region. The tabulation includes events not only from ARO at Lake Traverse (Lat. $45^{\circ} 57^{\prime} \mathrm{N}$ Long. $78^{\circ} 03^{\prime} \mathrm{W}$ ) but also from the Dominion Radio Astrophysical Observatory at Penticton, B.C. (Lat. $49^{\circ} 19^{\prime} \mathrm{N}$ Long. $119^{\circ} 37^{\prime} \mathrm{W}$ ). The latter observations are on the frequency of $2700 \mathrm{Mc} / \mathrm{s}$ which has been allocated to the radio astronomy service.

Tabulations of the bursts for the combined observing day of ARO and DRAO include the URANE code type as reported telegraphically, type in I.A.U. descriptive terms, the time of commencement in UT, duration in hours and minutes, mean flux, UT time of maximum flux and value of peak flux, and 
remarks. Many of the microwave bursts show a rise to a single maximum and subsequent decay. Three types of these "Simple" bursts are designated by the regions occupied in a scatter diagram of Burst Intensity versus Duration. These are shown in the figure and are described numerically in the table. Consideration of the rate of flux increase leads to further descriptions of the Simple bursts 2 as "Impulsive" and to the Simple bursts 3 as "Long Enduring" or as "Gradual Rise and Fall". Simple bursts 1 may be either Impulsive or Non-impulsive. Further description of these and other bursts requires a numerical measure of the degree of impulsiveness.

Varying degrees of complexity are noticed in the microwave bursts. Bursts with two or more peaks are termed "Complex" bursts. If the minumum flux between peaks reaches that of the quiet sun for a short interval, the composite event is termed a "Group", and individual listings of the components are provided. When the complexity is such that it is difficult to tabulate individual parts, the event is termed a "Period of Irregular Activity" or "Fluctuations". If this appears as a separate event, it is given a separate type-number in the URANE code, but if superimposed upon a Simple or Complex bursts as a secondary feature, it is not given a. URANE code number and is only recorded by the letter " $f$ " added to the basic descriptive term.

A gradual increase in flux which precedes the Impulsive burst is designated as a "Precursor".

Many bursts, both simple and Complex, are follorved by an enhanced level of great duration and designated as a "Post Burst Increase". If these two features, the Precursor and the Post Burst occur together and are simply connected, they are combined into a Simple $3 \mathrm{~A}$ burst.

Decreases in the quiet sun level are occasionally observed after Impulsive events and are designated as "Post Burst Decrease" of "Absorption".

Microwave bursts of great intensity, with peak intensity equal to or greater than 750 flux units are of special geophysical interest and are generally very complex. The secondary fluctuations are comparable to the average bursts so that these events have been placed in a group designated "Great Bursts". In the URANE code they are listed as Complex bursts. The level of intensity for burst classifications, 7.5 flux units, has been adopted since it is approximately $1 / 10$ of the quiet solar flux at sunspot minimum.

The commencement of a burst is taken when the enhancement of the daily flux shows a departure from the daily level by an amount of approximately 1 flux unit. For the Impulsive bursts this may be determined certainly to within a minute while for the Gradual Rise and Fall burst, the uncertainty in the time of commencement may be as great as 5 minutes. The letter "b" appearing before the time of start, indicates that the burst was already in progress at this time. Profiles of selected bursts are produced below.

From time to time photographic copies or tracings of the more interesting outstanding occurrences are published. 
MICROWAVE BURST TYPES - $2800 \mathrm{MC} / \mathrm{S}$ - OTTAWA, CANADA

SIMPLE 1

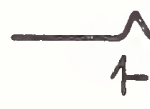

(1)

SIMPLE 2

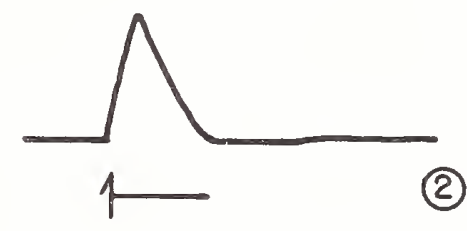

SIMPLE 3

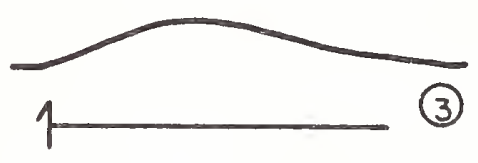

POST-BURST

INCREASE

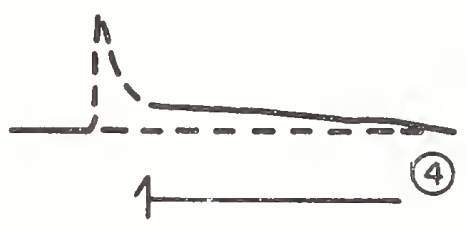

POST-BURST DECRE ASE

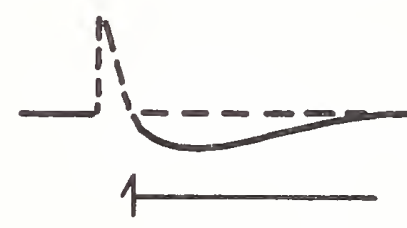

(5)

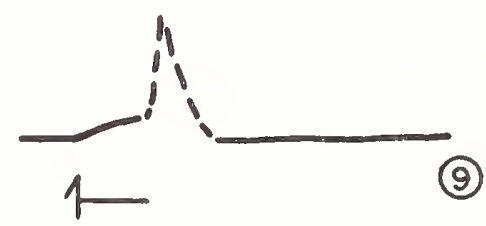

1 START

DURATION
COMPLEX

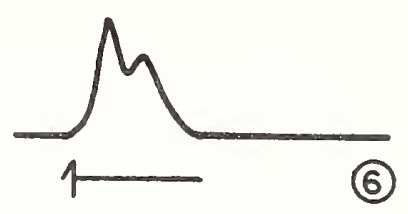

GROUP ( 3 )

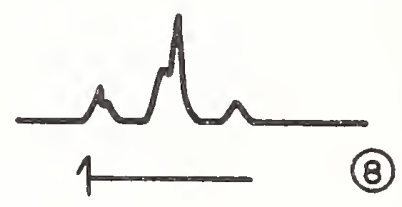

FLUCTUATIONS

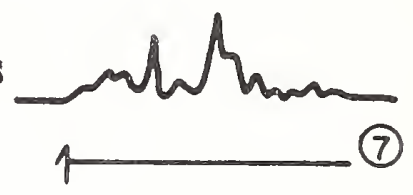

GREAT BURST - See Text

(6)

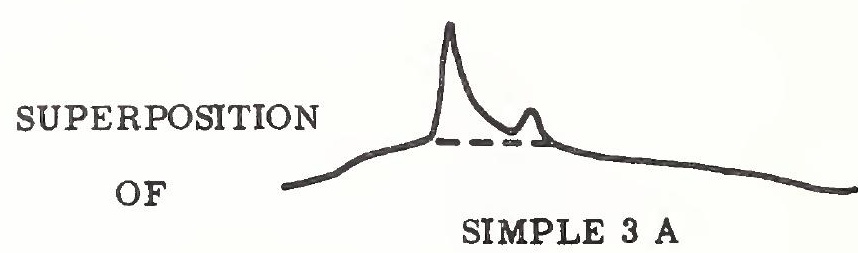

BURSTS

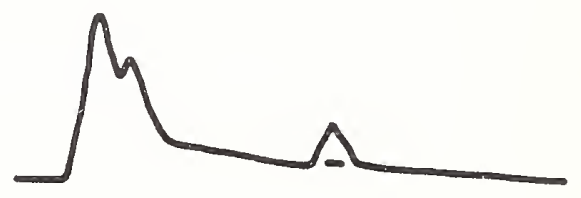

POST INCREASE A

URANE CODE TYPE

RELATION OF SIMPLE BURSTS TO DIAGRAM OF INTENSITY VERSUS DURATION

I

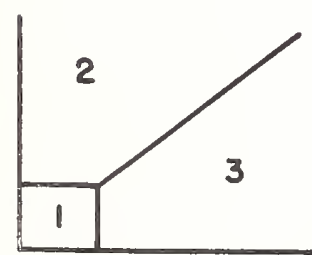

Region 1 - SIMPLE 1 : Intensity $\leq 7.5$ flux units Duration $\leq 7.5$ minutes May be impulsive

Region 2 - SIMPLE 2 : Intensity $>7.5$ flux units Impulsive

Region 3 - SIMPLE 3 : Duration $>7.5$ minutes 


\section{$223 \mathrm{Mc} / \mathrm{s}$ Solar Interferometric System}

The Geo-Astrophysics Laboratory of Boeing Scientific Research Laboratories operates a swept-lobe interferometer as part of its program of research in solar physics. The frequency of operation is $222.54 \mathrm{Mc} / \mathrm{s}$. Each of the two antenna arrays consists of eight 10-element Yagi antennas, equatorially mounted to track the sun. The baseline is 299 feet. A continuous measurement of the position of the radio center of gravity relative to its position at meridian transit is made through the use of a digitally operated phase-compensating device. Other detalls of the system are given in Boeing Document D1-82-0122, "Boeing Lobe Sweep Interferometer System", by John Lansinger and Ralph Gagnon, copies of which are available.

The data presentation is in the form of amplitude and phase recordings. Two quasi-logarithmic amplitude recorders are used. Of these the high sensitivity one reaches full scale deflection at a flux level a little greater than $70 \times 10^{-22}$ watts $/ \mathrm{m}^{2} / \mathrm{c} / \mathrm{s}$. Full scale deflection on the other corresponds to a flux of about $40,000 \times 10^{-22}$ watts $/ \mathrm{m}^{2} / \mathrm{c} / \mathrm{s}$. The phase recorder provides an indication of difference of phase between the burst and the radio center of gravity of the sun, from which the position of the burst can be estimated.

The burst data are described in accordance with the definitions given in the IAU Quarterly Bulletin on Solar Activity. Thus the symbols s, $c$, f and e refer to simple and complex variations of intensity, group of bursts, and sudden beginning of burst, respectively. Major bursts are those with a duration of about three minutes or more and with an energy content of the order, $750 \times 10^{-22}$ watts $/ \mathrm{m}^{2} / \mathrm{c} / \mathrm{s}$ or greater. The time of beginning and maximum are given in UT. Duration in minutes, peak and mean flux densities are also tabulated.

Note: This interferometer has been used on another research program than the solar one since August 1, 1963 and therefore solar noise observations have not been made since that date. However, it is planned to use the interferometer on the sun again beginning Apri1 1, 1965 and continuing through the IQSY Cooperative Study of Active Solar Regions period from April - September 1965.

$169 \mathrm{Mc} / \mathrm{s}$ Solar Interferometric Observations

The $169 \mathrm{Mc} / \mathrm{s}$ interferometric observations are recorded around local noon at Nançay, France, $\left(N_{4} 7^{\circ} 23^{\prime}, E 8^{m_{4}} 7^{\circ}\right)$, the field station of the Meudon observatory. The equipment is to undergo modifications towards the end of November 1964.

The main lobes are parallel to the meridian plane: the half-power width is 3.8 minutes of arc in the East-West direction and much larger than the solar diameter in the North-South direction. Following the modifications the main lobes are to be about $1^{\circ}$ apart (Ann. Astrophys. 20, 155, 1957). The records give the strip intensity distribution from the center of the disk to $30^{\prime}$ to the West and East. 
These daily distributions are plotted on the same chart giving diagrams of evolution (C.R. 244, 1460, 1957). Points of equa1 intensity given in relative units are joined day after day in the form of isophotes; these isophotes will be determined after the modified equipment is operating (about January 1965). A bracketed line indicates the width of the recorded lobe pattern in the East-West direction. A short East-West line is used where the source width is not known. The direction of the horizontal pip indicates whether the radio source is in the northern solar hemisphere (pip points toward earlier dates), or in the southern hemisphere (pip points towards later dates). If a pip extends on both sides of the line, the radio source was observed to be close to the solar equator. A circle or semicircle replaces the pip when the North-South coordinate of the position is unknown. For each radio noisy region the smoothed intensity around noon is given in $10^{-22}$ watts $/ \mathrm{m}^{2} / \mathrm{c} / \mathrm{s}$.

Note that the isophotes cannot be measured when a radio noisy region of large intensity is on the disk.

$108 \mathrm{Mc} / \mathrm{s}$ Solar Noise Observations

Data on solar radio emission at the niminal frequency of $108 \mathrm{Mc} / \mathrm{s}$ recorded at the Table Mesa (Boulder) station of the Central Radio Propagation Laboratories of the National standaxds are presented. The antenna is equatorially mounted and linearily polarized. The plane of polarization is paralle 1 to the solar rotation axis.

Note: Data on solar radio emission at $167 \mathrm{Mc} / \mathrm{s}$ recorded at the Gunbarrel Hill (Boulder) station of the National Bureau of Standards were terminated September 30, 1960. (See earlier CRPL-F Part B reports for details). The $108 \mathrm{Mc} / \mathrm{s}$ equipment started October 1, 1960.

Only the outstanding occurrences are reported. A scale of 1 to 3 is now used for the estimate of smoothed maximum flux where:

\footnotetext{
1 signifies $<10 \times$ quiet sun

2 signifies $>10<100 \times$ quiet sun

3 signifies $>100 \times$ quiet sun
}

Starting and maximum times in UT are read to the nearest $1 / 10$ minute if they are very definite and otherwise to the nearest minute. If the duration is less than five minutes, it is given to the nearest 1/10 minute: otherwise to the nearest minute. The following qualifying symbols are used:

$$
\begin{aligned}
E= & \text { Event in progress before observations began. } \\
D= & \text { Event continues after observations cease. } \\
S= & \text { Measurement may be influenced by inter- } \\
& \text { ference or atmospherics. }
\end{aligned}
$$

The types of the outstanding occurrences follow the classification origina11y described for $200 \mathrm{Mc} / \mathrm{s}$ observations by Dodson, Hedeman and Owren (Ap J. 118, 169, 1953). The types are identified by numbers which describe the character of the trace, but not the magnitude of the event, as follows: 
0 - Rise in base leve1 - A temporary increase in the continuum with duration of the order of tens of minutes to an hour.

1 - Series of bursts -- Burst or groups of bursts, occurring intermittently over an interval of time of the order of minutes or hours. Such series of bursts are assigned as distinctive events only when they occur on a smooth record or show as a distinct change in the activity.

2 - Groups of bursts -- A cluster of bursts occurring in an interval of time of the order of minutes.

3 - Minor burst -- A burst of moderate or sma 11 amplitude, and duration of the order of one or two minutes.

4 - Minor burst and second part -- A double rise in flux in which the early rise is a minor burst.

6 - Noise storm -- A temporary increase in radiation characterized by numerous closely spaced bursts, by an increase in the continuum, or by both. Duration is of the order of hours or days.

7 - Noise storm begins -- The onset of a noise storm occurs at some time during the observing period.

8 - Major burst -- An outburst, or other burst of large amplitude and more than average duration. A major burst is usually complex, with a duration of the order of one to ten minutes.

$9 A, 9 B$ or 9 -- Major burst and second part or large event without distinct first and second parts $\cdots$ If there is a double rise in flux, the first part, a major burst, is listed as $9 \mathrm{~A}$ and the second part as $9 B$, The second part may consist of a rise in base leve1, a group or series of bursts, a noise storm. A major increase in flux with duration greater than ten minutes but without distinct first and second parts, is listed simply as 9.

O-RISE IN BASE LEVEL

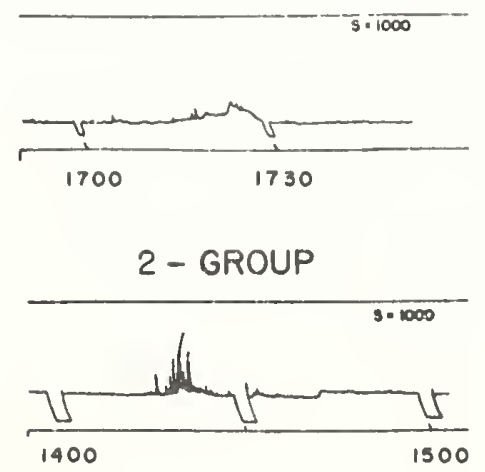

I- SERIES

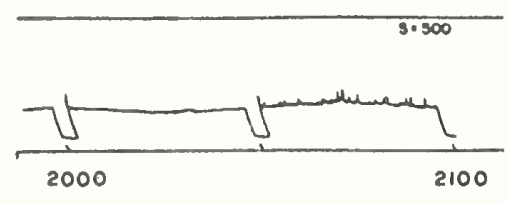

3- MINOR

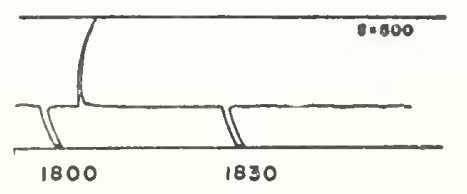


4 - MINOR+

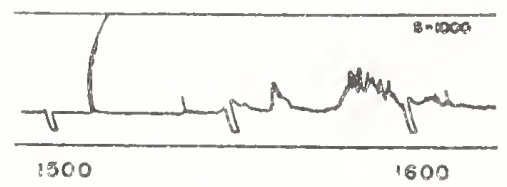

7 - ONSET OF NOISE STORM

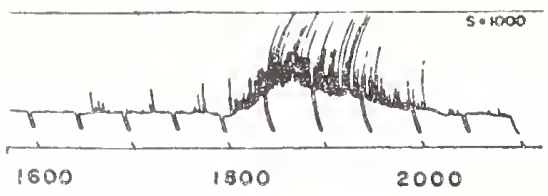

6-NOISE STORM IN PROGRESS

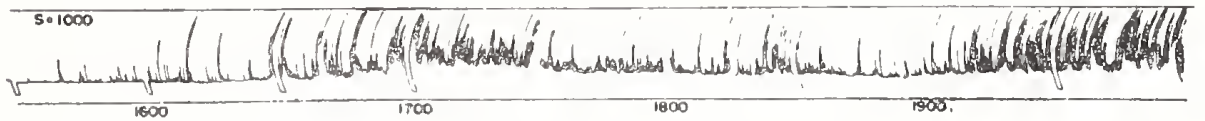

8- MAJOR
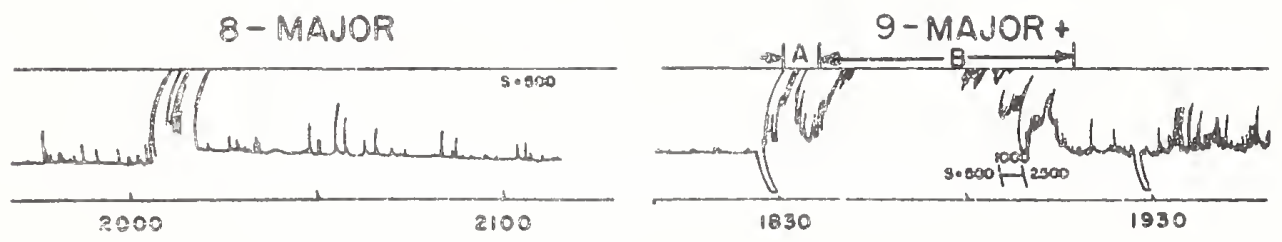

Notes: In the present table, the type classification 0 is not used: it has been included above only for information.

In the nominal times of observation table, the times preceded by I signify periods of interference that could mask solar events.

From time to time photographic copies of the more interesting outstanding occurrences are published.

Solar Spectral Observation a Fort Davis

Data are presented on solar radio emission in the spectral range 50-320 Mc/s recorded at the Radio Astronomy Station of Harvard College observatory, Fort Davis, Texas. The research program is supported by financial assistance from the Air Force Cambridge Research Laboratories through the Sacramento Peak Observatory. The equipment used at the Station has been described elsewhere (Thompson, Astrophys. J. 133, 643, 1961). The following activity is listed: limited information on noise storms (type I); slow-drift bursts (type II); groups of fast-drift bursts with more than 10 individual butsts (type IIIG); continuum bursts (type IV). Idealized examples of the bursts are shown below: 

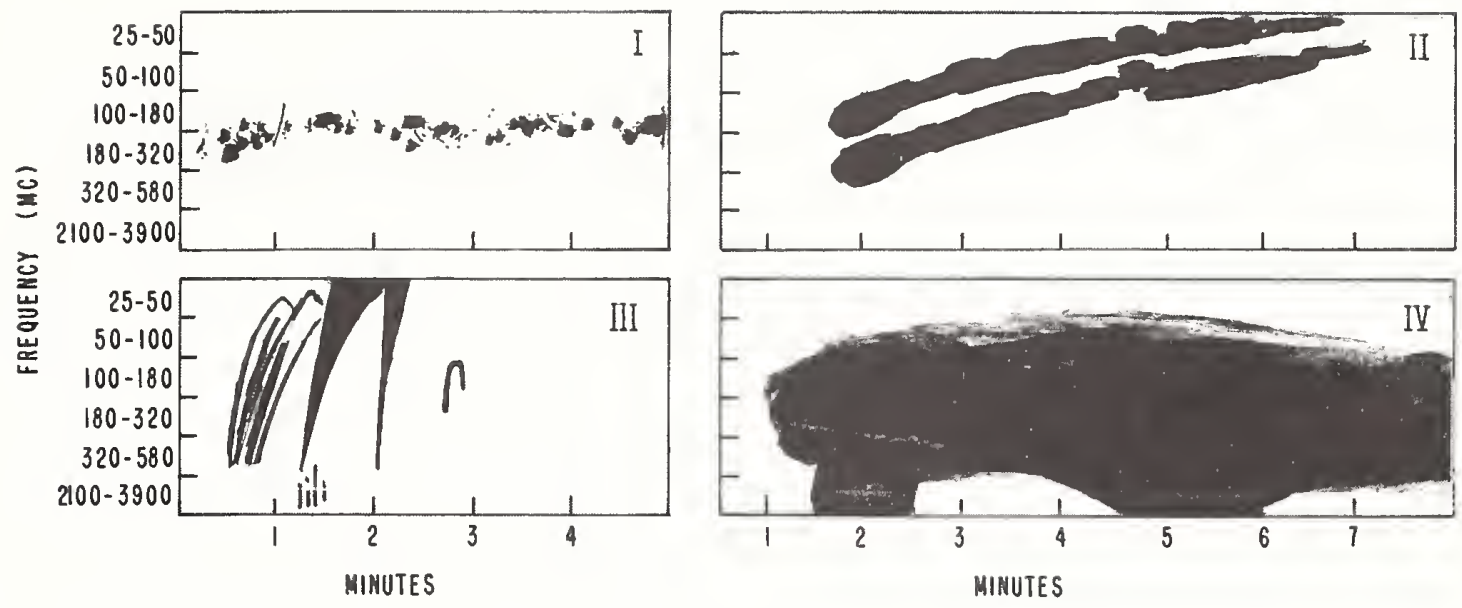

Observations are made for ten hours daily (see UT times listed in column 1 of the table). Entries in the tables are given in Universa 1 Time (UT), and the accuracy is to the nearest half minute, except in the case of major outbursts which are specified to the nearest 0.1 minute. Three classes of intensity are listed: 1 (faint), 2 (moderate), and 3 (strong). At $100 \mathrm{Mc} / \mathrm{s}$ these correspond to 5-40, 40-200, and >200, $\mathrm{x} 10^{-22}$ watts $/ \mathrm{m}^{2} / \mathrm{c} / \mathrm{s}$, respective $1 \mathrm{y}$. The frequency range in $\mathrm{Mc} / \mathrm{s}$ for the burst is also given as well as additional remarks when appropriate.

\section{Solar Spectral Observations High Altitude Observatory, Boulder, Colorado}

The research program is supported by the Electronics Research Directorate, Air Force Cambridge Research Laboratories and Goddard Space Flight Center, National Acronautics and Space Administration.

The spectral range is from 7.6 to $41 \mathrm{Mc} / \mathrm{s}$ scanned in 0.65 seconds. The collecting area of the antennas is approximately 1000 square meters, in two corner reflectors forming an interferometer pair. Observations are taken routinely throughout the Boulder observing day from about 1400 UT to $2400 \mathrm{UT}$. On the low-frequency side, bursts are frequently limited by an external reflection of the waves above the ionosphere. Examples of Type III (fast drift) and continuum records taken with this equipment are published in A. Boischot, R. H. Lee, and J.W. Warwick, Ap. J., 131,61 (1960). An example of Type II (slow drift) and Type IV burst is included herewith; the Type II is detected not only by means of the (relatively smal1) enhancement it produces against a background of continuum, but also by means of the fast fluctuations of fringe position produced as the burst drifts through the low-frequency range. Continuum of two kinds is reported: (a) in close association with Type III burst storms, and often also with reverse drift bursts. This is described 
simply as "continuum" and is often, but not always, associated with noise storms on metric wavelengths; (b) following major outbursts of Type III or Type II associated with flares. These latter cases of continuum are labelled Type IV in the tables; the attached photograph illustrates an outstanding example. Intensities are on a rough scale from 1- to 3+, crudely convertible to flux densities as follows:

$$
\begin{aligned}
& 1 \text { - to } 1+; 5 \times 10^{-22}<s<2 \times 10^{-21} \\
& 2 \text { to } 2+; 2 \times 10^{-21}<s<8 \times 10^{-21} \\
& 3 \text { to } 3+; 8 \times 10^{-21}<\leq 3 \times 10^{-20}
\end{aligned}
$$

Above about $3 \times 10^{-20}$ watts $\mathrm{m}^{-2}$ (cps) ${ }^{-1}$, the equipment saturates and does not indicate relative intensities satisfactorily.

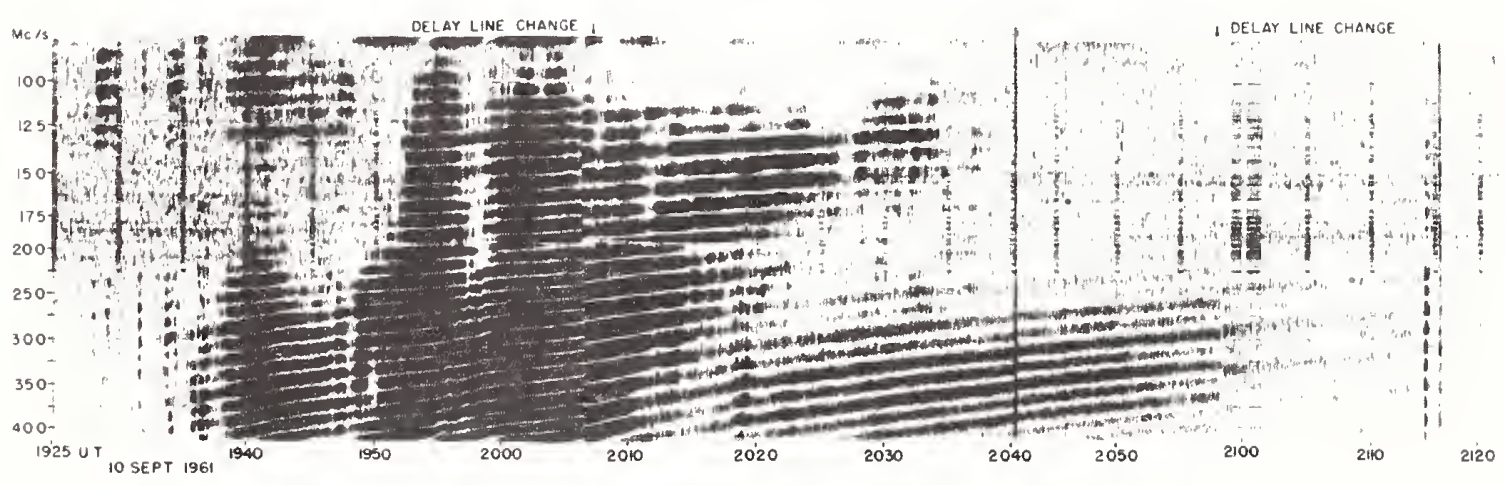

The times of beginning and ending are given in UT. Symbol "b" used for in progress before time given and "a" for end after time given. The frequency range for the burst is also given.

\section{$9.1 \mathrm{~cm}$ Solar Spectroheliograms}

A daily series of radio spectroheliograms obtained with a 3 minuteof-arc pencil-beam antenna located at the Radio Astronomy Institute of the Stanford University, Stanford, California (N $37^{\circ} 24^{\prime}, W 122^{\circ} 11^{\prime}$ ), are presented. This program is supported by CRPL through National Science Foundation assistance.

The maps show the distribution of radio emission across the solar disk at a wavelength of $9.1 \mathrm{~cm}$ by means of brightness temperature values. The brightness unit, which varies from map to map, is usually about $3000^{\circ} \mathrm{K}$. Its value is determined after each map is plotted by reference to the flux density, $S$, of the whole sun as measured by Covington at $10.7 \mathrm{~cm}$ wavelength. Readings of constant brightness temperature equal to or greater than 20 are underlined. A total of all readings, flux-density $\mathrm{S}$ at $10.7 \mathrm{~cm}$ in units of $10^{-22} \mathrm{w} \mathrm{m}^{-2} \mathrm{cps}^{-1}$, and brightness unit in ${ }^{\circ} \mathrm{K}$ are presented at the bottom of each map. The axis of rotation of the sun is shown by a curly arrow placed near the North Pole. A circle shows the photosphere: a correction has been applied for the variation of the sun's semi-diameter, so that 
the photospheric circle is reproduced with a constant diameter of $5 \mathrm{~cm}$. This is an integral submultiple of the IAU standard of $15 \mathrm{~cm}$ used on the full size originals, which are available on request from the Stanford Radio Astronomy Institute. A set of Stonyhurst disks with a diameter of $5 \mathrm{~cm}$ is reproduced on transparent paper at the end of this text.

A detailed description of the stanford microwave spectroheliograph has been given by Bracewe 11 and Swarup (IRE Trans., Vol. AP 9, January 1961). The instrument scans the sun from West to East with rotation of the earth. At the end of each scan, pencil-beams are shifted in a NorthmSouth direction by means of 16 variable phase-shifters placed in the North-South array. The stanford spectroheliograph has been digitized so that the finished maps are available within a few hours after the observations. A positional accuracy of better than $\pm 1 / 2$ minute-of-arc in the location of bright features is maintained.

Observations are made each day near local noon. The width of the antenna beams which scan the sun change from nearly $3^{\prime} \times 3^{\prime}$ in mid-summer to nearly $3^{\prime} \times 6^{\prime}$ in mid-winter. At a declination $\delta$ on the meridian the beamwidths are 3.1 minutes East-West and $3.1 \mathrm{sec}(38: 2-\delta)$ Nortb-South. The theoretical response of the antenna to a point source is shown below. Further details are given in the above mentioned reference. The response to a source of finite size is the convolution of this pattern with the source distribution. The subsidiaxy lobes, which are positive and negative, may be reduced by smoothing the maps but this would also widen the primary beam. A simple procedure for smoothing is to average four alternate values located at the corner of a rectangle with horizontal and vertical sides. Any spurious lobes arising because of antenna maladjustments are kept in control by periodic phase adjustment of the antenna.
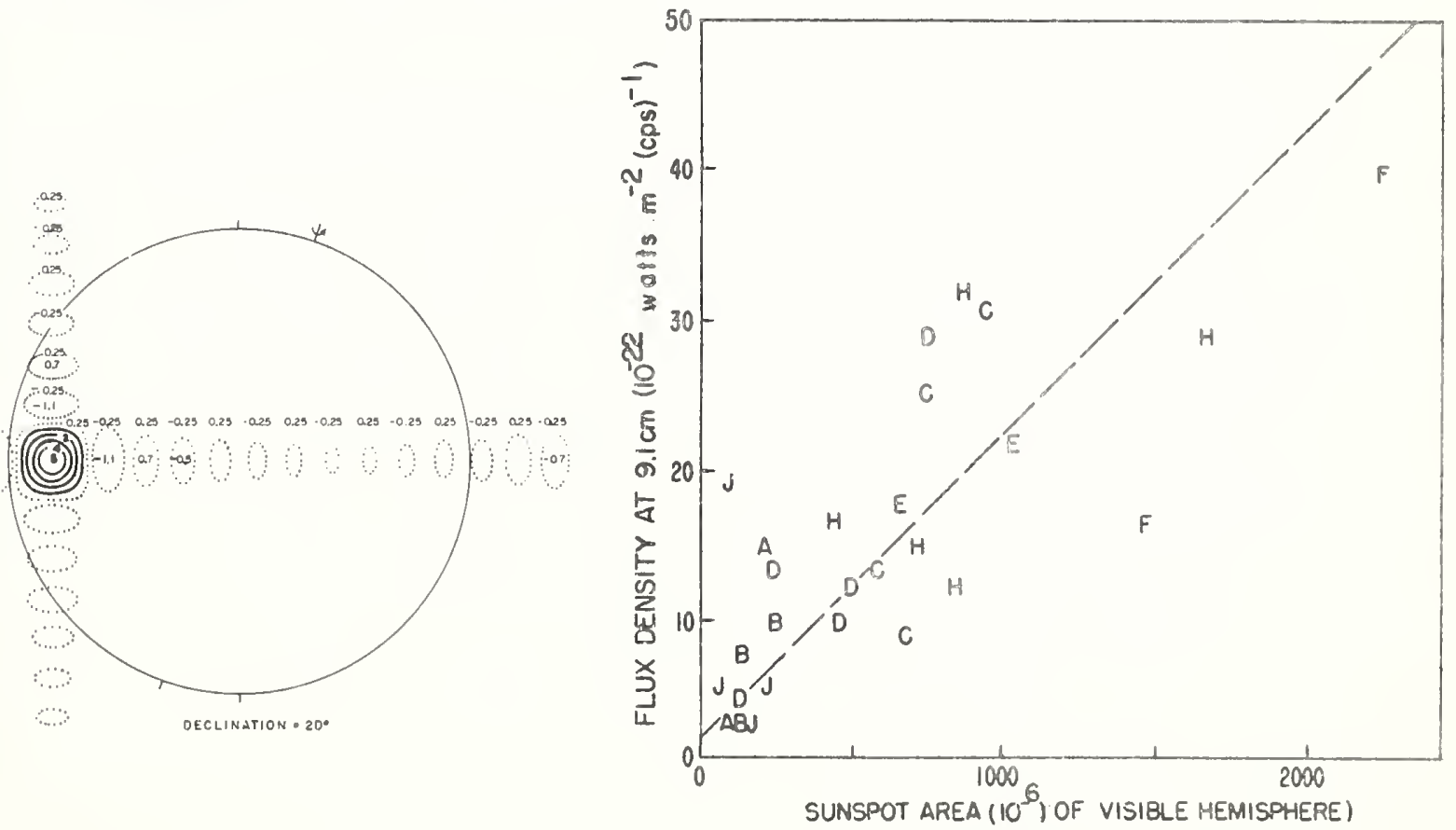

FIG. I SCATTER DIAGRAM SHOWING THE RELATION BETWEEN RADIQ FLUX AND SUNSPOT AREA 
Results of a preliminary investigation of the $9.1 \mathrm{~cm}$ solar maps have been reported by Swarup (Stanford Electronics Laboratories Scientific Report No. 13 under Contract AF 18 (603) 53, 1961). Recently it has been found that the size of many strong sources at $9.1 \mathrm{~cm}$ is 1 ess than that of the antenna beam. Therefore, for strong sources, peak brightness temperatures in the $9.1 \mathrm{~cm}$ maps are lower than actual by a factor of more than 3 or 4 .

A relation between flux densities of radio sources and area of the associated sunspots is shown above. Each point is represented by a letter denoting Zurich classification of sunspot groups. For a strong source, the flux density decreases to about $25 \%$ as the region rotates from the central meridian to the limb. For a weak region, there is less variation. The flux density of a localized region may be found by taking a total of all the readings over the area concerned, subtracting an estimated background, dividing by the total for the day, and multiplying by $\mathrm{S}$. For a compact source, an approximate value of flux density in units of $10^{-22} \mathrm{w} \mathrm{m}^{-2} \mathrm{cps}^{-1}$, can be readily obtained by multiplying peak brightness temperature by a factor $3 \times 10^{-5} \mathrm{sec}(38.2-\delta)$, where $\delta$ is the declination of the sun.

\section{COSMIC RAY INDICES}

The tables and chart present the scaled hourly count rate average for each 24 hour interval (Universal Time) for four high counting rate neutron monitors. The monitors have different values of magnetic cut-off rigidity, while the asymptotic cones of acceptance of the four "look" in essentially the same direction in space. The four sets of data can therefore be used to estimate the rigidity dependence of fluctuations which occur in the primary cosmic radiation.

The characteristics of the four stations can be summarized as follows:

\begin{tabular}{|c|c|c|c|c|}
\hline Station & Churchill & Deep River & Climax & Dallas \\
\hline Geographic Latitude & $58^{\circ} 45^{\prime} \mathrm{N}$ & $46^{\circ} 36^{\circ} \mathrm{N}$ & $39^{\circ} 22^{\prime} \mathrm{N}$ & $36^{\circ} 47^{\prime} \mathrm{N}$ \\
\hline Geographic Longitude & $94^{\circ} 05^{\circ} \mathrm{W}$ & $77^{\circ} 30^{\circ} \mathrm{W}$ & $106^{\circ} 11^{\prime} \mathrm{W}$ & $91^{\circ} 04^{\circ} \mathrm{W}$ \\
\hline $\begin{array}{l}\text { Vertical Cut off } \\
\text { rigidity }\end{array}$ & $<0.21 \mathrm{BV}$ & $1.02 \mathrm{BV}$ & $3.03 \mathrm{BV}$ & $3.98 \mathrm{BV}$ \\
\hline Altitude & $39 \mathrm{M}$ & $145 \mathrm{M}$ & $3400 M$ & $208 M$ \\
\hline Detector & NM64 & NM6 4 & IGY & NM64 \\
\hline
\end{tabular}


The Climax, Colorado, USA, neutron monitor, station number B305, data are communicated by J. A. Simpson and G. Lentz of the Enrico Fermi Institute for Nuclear Studies, University of Chicago. The instrument is a standard Chicago type neutron monitor, utilizing 12 BF3 counter tubes. The station has a mean baremetric pressure $P=504.0 \mathrm{~mm}$ Hg. For a more detailed description of the neutron intensity monitor and its associated electronics see J. A. Simpson, Annals of the IGY, Vol. IV: Part VII, pages 351-373 (1957). The following correction factor is used at Climax:

$$
R_{\operatorname{corr}}=R_{o b s} e^{\delta P / L}
$$

where $\delta_{\mathrm{P}}=\mathrm{P}-\mathrm{P}_{\mathrm{obs}}$, the mean minus the observed pressures, and $\mathrm{L}$ is the $\mathrm{ab}-$ sorption mean free path of $106.0 \mathrm{~mm} \mathrm{Hg}$. The data are in scaled counts per hour; the scaling factor being 128. The publication of these data in this monthly CRPL series began september 1960. Earlier data, beginning June 1957, are available in bihourly form at the IGY World Data Center A for Cosmic Rays.

The chart depicts the variations of cosmic ray intensity recorded by a neutron monitor at Deep River, Ontario, Canada, as submitted by H. Carmichae 1 and J. F. Steljes, of Atomic Energy of Canada Jimited, Chalk River, Ontario. The vertical scale lines mark the days of the month in Universal Time: the horizontal scale lines are at intervals of $5 \%$ based upon 555,000 counts per hour (after barometric correction) arbitrarily taken as $100 \%$. The charts have been published from January 1959, publication beginning in the November 1960 issue. From May 1962 the readings have been taken from a new monitor, ten times as large as the one used previously. Prior to May 1962 the 100\% level was 55,500 counts per hour. A preliminary barometric coefficient was used for the new monitor from May 1962 until October 1962. In the March 1963 issue final revised charts were published for these six months using a better value of the barometric coefficient.

The Dallas, USA, and Churchi11, Canada, neutron monitors follow the IQSY design described by Carmichae1 (IQSY NOTES, 非 7)。 The data from DaIlas and Churchill have been corrected to constant atmospheric pressures of $1000 \mathrm{mb}$, and $1010 \mathrm{mb}$, respectively using an attenuation length of 139.9 grams $\mathrm{cm}^{-2}$. Scaling factors of 120 are employed in both installations. The data have not been corrected for the minor changes $(<1 \%$ ) in efficiency of monitor which inevitably occur over any appreciable period of time. The Dallas monitor is operated by $\mathbb{K}$. G. McCracken and U. R. Rao at the Graduate Research Center of the Southwest, Dallas, Texas, while the Churchill monitor is operated by the above, in collaboration with D. C. Rose of the National Research Council of Canada. The Defence Northern Research Laboratories of Canada is responsible for the day-to-day maintenance of the Churchill monitor. The Dallas monitor commenced operation on December 1 , 1963, while the Churchill monitor commenced operation on April 18, 1964. Hourly mean data from both installations are routinely distributed to the scientific community on a monthly basis by the Cosmic Ray Laboratory, Graduate Research Center of the Southwest, P. O. Box 30365, Dallas 30, Texas, USA. 


\section{GEOMAGIVETIC ACTIVITY INDICES}

C, Kp, Ap, and Selected Quiet and Disturbed Days -- The data in the table are: (1) preliminary international character figures, C; (2) geomagnetic planetary three-hour range indices, $\mathrm{Kp} ;$ (3) daily "equivalent amplitude", Ap; (4) magnetically selected quiet and disturbed days.

This table is made available by the Comittee on Characterization of Magnetic Disturbances of IAGA, IUGG. The Meteorological Office, De Btlt, Holland collects the data from magnetic observafories distributed throughout the world, and compiles $\mathrm{C}$ and selected days. Gottingen University computes the planetary and equivalent amplitude indices. The same data are also published in the Journal of Geophysical Research along with data on sudden commencements (sc) and solar flare effects (sfe), and principal magnetic storms.

The C-figure is the arithmetic mean of the subjective classification by all observatories of each day's magnetic activity on a scale of 0 (quiet) to 2 (storm).

$\mathrm{Kp}$ is the mean standardized $\mathrm{K}$-index from 12 observatories between geomagnetic latitudes 47 and 63 degrees. The scale is 0 (very quiet) to 9 (extremely disturbed), expressed in third of a unit, e.g. 5 - is 4 and $2 / 3,50$ is 5 and $0 / 3$, and $5+$ is 5 and $1 / 3$. This planetary index is designed to measure solar particle-radiation by its magnetic effects, specifically to meet the needs of research workers in the ionospheric field. A complete description of $\mathrm{Kp}$ has appeared in Bulletin 12b, "Geomagnetic Indices $\mathrm{C}$ and $\mathrm{K}$, 1948 " of the Association of Terrestrial Magnetism and Electricity (IATME), International Union of Geodesy and Geophysics.

Ap is a daily index of magnetic activity on a linear scale rather than on the quasi-logarithmic scale of the $K$-indices. It is the average of the eight values of an intermediate 3-hourly index "ap", defined as one-half the average gamna range of the most disturbed of the three force components, in the three-hour interval at standard stations; in practice, ap is computed from the $\mathrm{Kp}$ for the 3-hour interval. The extreme range of the scale of Ap is 0 to 400. The method is described in IATME Bulletin No. $12 \mathrm{~h}$ (for 1953) p. vilif. Vajues of $\mathrm{Ap}$ ( 1 ike $\mathrm{Kp}$ and $\mathrm{CP}$ ) have been published for 1932 to 1961 in IAGA Bulletin No. 18 by J. Bartels, distributed by North-Holland Pub lishing Company, Amsterdam.

The magnetically quiet and disturbed days are selected in accordance with the general outline in Terr. Mag. (predecessor to J. Geophys. Res.) 48, pp. 219-227, December 1943. The method in current use calls for ranking the days of a month by their geomagnetic activity as determined from the following three criteria with equal weight: (1) the sum of the eight Kp's; the sum of the squares of the eight $\mathrm{KP}^{\mathrm{i}} \mathrm{s}$; and (3) the greatest Kp.

\section{Chart of Kp by Solar Rotations -- Monthly the graph of Kp for four} solar rotations is furnlshed through the courtesy of the Geophysikalisches Institute, Gottingen. Annually a graph of the whole year by solar rotations 
is included. From time to time another 27-day rotation chart depicting the daily geomagnetic character figure, C9, is presented.

\section{RADIO PROPAGATION QUALITY INDICES}

One can take as the definition of a radio propagation quality index: the measure of the efficiency of a medium-powered radio circuit operated under ideal conditions in all respects, except for the variable effect of the ionosphere on the propagation of the transmitted signal. The indices given here are derived from monitoring and circuit performance reports, and are the nearest practical approximation to the ideal index of propagation quality.

Quality indices are expressed on a scale that ranges from one to nine. Indices of four or less are generally taken to represent significant disturbance. (Note that for geomagnetic $\mathrm{K}$-indices, disturbance is represented by high numbers). The adjectival equivalents of the irtegral quality indices are as follows:

$$
\begin{array}{lll}
1=\text { useless } & 4=\text { poor-to-fair } & 7=\text { good } \\
2=\text { very poor } & 5=\text { fair } & 8=\text { very good } \\
3=\text { poor } & 6=\text { fair-to-good } & 9=\text { excellent }
\end{array}
$$

CRPL forecasts are expressed on the same scale. The tables summarizing the outcome of forecasts include categories P-Perfect; S-Satisfactory; U-Unsatisfactory; F-Failure. The following conventions apply:

P - Forecast quality equal to observed.

S - Forecast quality one grade different from observed.
U - Forecast quality two grades different from observed when both forecast and observed were $\geq 5$, or both $\leq 5$.

F - Other times when forecast quality two or more grades difference from observed.

Full discussion of the reliability of forecasts requires consideration of many factors besides the over-simplified summary given.

The quality figures represent a consensus of experience with radio propagation conditions. Since they are based entirely on monitoring or traffic reports, the reasons for low quality are not necessarily known and may not be limited to ionospheric storminess. For instance, low quality may result from improper frequency usage for the path and time of day. Although, wherever it is reported, frequency usage is included in the rating of reports, it must often be an assumption that the reports refer to optimum working frequencies. It is more difficult to eliminate from the indices conditions of low quality for reasons such as multipath or interference. These considerations should be taken into account in interpreting research correlations 
between the Q-figures and solar, auroral, geomagnetic or similar indices.

North Atlantic Radio Path -- The CRPL quality figures, Qa, are compiled bythe CRPI Forecasting Center at Ft. Belvoir, Virginia, from radio traffic data for North Atlantic transmission paths closely approximating New York-to-London. These are reported to CRPL by the Canadian Defence Research Board, Canadian Broadcasting Corporation, and the following agencies of the U.S. Government: -- Coast Guard, Navy, Army Signal Corps, U.S. Information Agency. Supplementing these data are CRPL monitoring, direction-finding observations and field-strength measurements of North At lantic transmission made at Belvoir.

The original reports are submitted on various time intervals. The observations for each 6 -hour interval are averaged on the original scale. These 6 -hour indices are then adjusted to the 1 to 9 quality-figure scale by a conversion table prepared by comparing the distribution of these indices for at least four months, usually a year, with a master distribution determined from analysis of the reports originally made on the 1 to 9 quality-figure scale. A report whose distribution is the same as the master is thereby converted linearly to the Q-figure scale. The 6-hourly quality figure is the mean of the reports available for that period.

The 6-hourly quality figures are given in this table to the nearest one-third of a unit, e.g. 50 is 5 and $0.3 ; 5-$ is 4 and $2 / 3$; $5+$ is 5 and $1 / 3$. Other data included are:

(a) Whole-day radio quality indices, which are weighted averages of the four 6-hourly indices, with half weight given to quality grades 5 and 6 . This procedure tends to give whole-day indices suitable for comparison with whole-day advance forecasts which seek to designate the days of significant disturbance or unusually quiet conditions.

(b) Short-term forecasts, issued every six hours by the North At lantic Radio Warning Service. These are issued one hour before $00 \mathrm{~h}, 06 \mathrm{~h}$, $12^{\mathrm{h}}, 18^{\mathrm{h}}$, UT and are applicable to the period 1 to 7 hours ahead.

(c) Advance forecasts\% (CRPL-J) are issued once a week and are applicable to 1 to 7 days ahead. They are modified as necessary by one of two types of the Special Disturbance Warnings applicable 1 to 6 days ahead (CRPL-SDW or CRPL-JC supplement). The forecast entitled "final" consists of the most recent of the above forms and is scored against the whole-day quality index.

(d) Half-day averages of the geomagnetic $\mathrm{K}$ indices measured by the Fredericksburg Magnetic Observatory of the U.S. Coast and Geodetic Survey.

* Beginning November 1, 1964 a new series of reports, CRPL-Jc replaced the former CRPL-J and-Jp reports. Quality figures are forecast for HF radio propagation conditions on typical high latitude paths passing through or near the auroral zone. They are scored against the average of the whole day North Atlantic and North Pacific quality figures. 
Note: Beginning with data for September 1955, Qa has been determined from reports that are available within a few hours or at most within a few days, including for the first time, the CRPL observations. Therefore these are the indices by which the forecasters assess every day the conditions in the recent past. Over a period of several years, they have closely paralleled the Qa indices which excluded CRPL observations and included three additional reports received after a considerable lag. Qa was first published to the nearest one-third of a unit at the same time.

North Pacific Radio Path -- The CRPL quality figures, Qp, are compiled by the CRPL High Latitude Space Environment Monitoring Station, at Anchorage, Alaska from measurements made at the station of field-strength and fadingrate characteristics on several suitable transmissions and on absorption characteristics as measured by riometer. These data indicate propagation conditions for moderately long transmission paths in the North Pacific equivalent to Seattle-to-Anchorage or Anchorage-to-Tokyo.

The original data are reported on various scales and for various time intervals. The observations for each 8 -hour period are averaged on the original scale. This average is compared with reports for the same period in the preceding two months and expressed as a deviation from the 3 -month mean. The deviations are put on the 1 to 9 scale of quality which is assumed to have a standard deviation of 1.25 and a mean for the various periods as follows:

$$
\begin{aligned}
& \text { 03-1.1 hours UT 5.67 19-02 hours UT } 6.00 \\
& \begin{array}{llll}
11-18 & 5.33 & 00-24 & 5.67
\end{array}
\end{aligned}
$$

The 8-hour and 24-hour indices QP are determined separately. Each index is weighted mean of the data available for the period.

The table includes the 8-hourly* quality figures: whole day quality figures; short-term forecasts issued by NPRWS** three times daily at $02 \mathrm{~h}$, $09^{h}$ and $18^{\mathrm{h}} \mathrm{UT}$, applicable to the stated 8-hour periods; advance forecasts issued weekly by NPRWS (CRPL-Jp report) modified as necessary by special Disturbance Warning (CRPL-SDW) and supplementary forecasts (CRPJ-JPs); and half-day averages of geomagnetic $K$ indices from sitka.

NOTE: From March 15, 1959 to August 1963 the short-term forecast schedule was twice daily and the North Pacific quality figures used for evaluation were 12 -hourly during that period.

* Within a few months 6-hourly North Pacific quality figures will replace the 8-hourly ones. These will be on the same time groupings as the quality figures for the North Atlantic area in order to permit easier intercomparisons between the regions.

** As of November 1, 1964 short term quality figure forecasts for the North Pacific area were terminated. Instead a daily advisory statement is now issued at Anchorage, Alaska describing current conditions and updating the whole day forecast issued on the CRPL-Jc report. 
Comparison Charts

A chart compares the North Atlantic short-term forecasts with the 6hourly Qa-figures. A second chart* compares the outcome of the final North Atlantic and North Pacific advance forecasts with a type of "blind" forecast. For the latter, the frequency for each quality grade, as determined from the distribution of quality grades in the four most recent months of the current season, is partitioned among the grades observed in the current month in proportion to the frequencies observed in the current month.

\section{Useful Frequency Ranges}

Ranges of useful frequencies on the North Atlantic radio path are shown in a series of diagrams, one for each day. The shaded area indicates the range of frequencies for which transmissions of quality 5 or greater were observed. The blacker the diagram, the quieter the day has been: a narrow strip indicates either high LUHF, low MUF, or both. These diagrams are based on data reported to CRPL by the German Post office through the Fermeldetechnischen Zentralamtes, Darmstadt, Germany, being observations every one and a half hours of selected transmitters located in the eastern portion of North America. Since January 6, 1958 the transmitters monitored are restricted to those located north of $39^{\circ}$ latitude. The magnetic activity index, AFr, from Fredericksburg, Va., is also given for each day.

\section{ALERT PERIODS}

The table gives the Advance Geophysical Alerts as initiated by the Western Hemisphere Regional Warning Center at Ft. Belvoir, Va., and also the Worldwide Geophysical Alerts as designated by the IQSY-IUWDS World Warning Agency, Ft. Belvoir, Va.

Beginning October 1, 1963 these alerts have been of the types recommended for the International Years of the Quiet Sun (IQSY). A full description of the program will be found in IQSY Instruction Manual No. 1 WORLD DAYS, which is available from the IQSY Secretariat, 6 Cornwall Terrace, London NW1, England. Pertinent information from the manual is quoted below.

Types of Alerts: Alerts are issued on two time scales: Advance Alerts are prompt and are distributed regionally; GEOAIERTS are slower and have world-wide distribution. The categories of phenomena described are magnetic storms, magnetic calm, solar flare, general solar activity, solar quiet, cosmic events and stratospheric warmings.

Alerts issued by a Regional Warning Center (or an individual geophysical institution or station) are called Advance Alerts (in telegrams: ADALERT). These may be issued at any time of day as may be practical, as soon as the phenomenon is observed or recognized. ADALERTS are distributed mainly in the region of origin, but are also interchanged among the RWCs.

* Beginning with November 1964 data the second chart will compare the outcome of the final CRPL-Jc advance forecast with the average of the whole day North At lantic and North Pacific quality figures. 
Alerts issued by the World Warning Agency are called GEOALERTS. They are issued daily at a stated time of day, $0400 \mathrm{UT}$. They are given extensive and world-wide distribution, mainly through the WMO telecommunications network.

Magnetic Storm Alert (MAGSTORM) is issued when a significant geomagnetic storm with $\mathrm{Kp}$ index of 5 or more is (a) expected, (b) has just started, or (c) is in progress. If appropriate, the degree of geophysical interest of the storm may be indicated by supplementary words (d) aurora observed, (e) aurora probable (if $\mathrm{K}$-index reaches 7) or (f) cosmic-ray Forbush decrease (COSRAY DECREASE) $>2 \%$ on a neutron monitor.

Magnetic Calm Alert (MAGCALME) is issued when geomagnetic activity is unusually low and no significant disturbance is expected within the next 24 hours.

Solar Flare Alert (SOFLARE) is issued when a relatively important solar flare has been observed; the nominal time of the flare is given. Issued only as regional Advance Alerts.

Solar Activity Alert (SOLACTIVITY) is issued when the general leve 1 of solar activity is relatively high because of the presence of one or more active centers on the solar disc.

Solar Calm Alert (SOLCALME) is issued when the sun is extremely quiet. Geophysical stations will be alerted that there is a relative minimum in solar activity. Solar observatories should be on the lookout for the birth of a new region on the sun.

Cosmic Event Alert (COSMIC EVENT) is issued when there is evidence for the first or continued arrival of energetic solar particles at the earth. The degree of geophysical interest of the event is indicated by the supplementary information (a) cosmic-ray increase (COSRAY INCREASE) or (b) polar cap ionospheric absorption event (POLCAP ABSORPTION).

Stratospheric Warming Alert (STRATWARM) is issued when a sudden and unusual increase in temperature at $30 \mathrm{~km}$ or above has been detected. The general geographical region where the warming phenomena have been observed is specified; such events however, usually involve the high level circulation of the entire hemisphere at high latitudes after a period of several days, and an estimate of the area to be effected is given.

Timing information:

(i) if phenomenon has already started the nominal UT time of start is given by a date-time group: JJHHmmZ, where JJ is date; HHmm is hours and minutes, UT; and $\mathrm{Z}$ is conventional symbol to indicate UT. (Example: 220613Z - 22nd day, 06 hours 13 minutes UT.);

or (ii) if phenomenon is in progress, indicate by the word EXISTS:

or (iii) if phenomenon is predicted, indicate by the word EXPECTED; 
and elaboration:

(i) for MAGSTORM, can add words AURORA OBSERVED or AURORA PROBABLE or COSRAY DECREASE, if appropriate;

(ii) for COSMIC EVENT, can add words COSRAY INCREASE or POLCAP ABSORPTION;

(i1i) for SOLACTIVITY, can add words FLARES or EAST LIMB or GAMMA SUNSPOT or RADIO SPOT or NEW REGION BORN, if appropriate.

or Geographical Region of initial detection and movement expected, used only in connection with STRATWARM. (Example: ORIGIN WEST EUROPE MOVING CANADA).

\section{INDEX FOR CRPL-F PART B}

On the following pages the index gives the number of the CRPL-F Part $B$ report or reports in which data for any month in question will be found beginning with January 1963. The index for July 1957 through December 1959 data was published with the November 1961 descriptiva text. The index for January 1960 through December 1961 was published with the November 1962 descriptive text. The index for January 1962 through December 1962 was published with the November 1963 descriptive text. Copies of these indices are available upon request. 
范

ป $\quad$ 궈ำ

มุล

覀

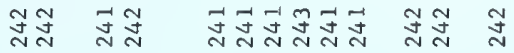

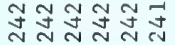

孛

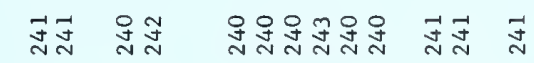

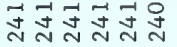

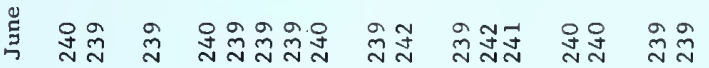

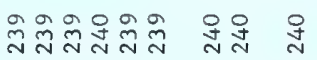

웍원월

㠃

స్ల

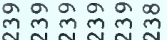

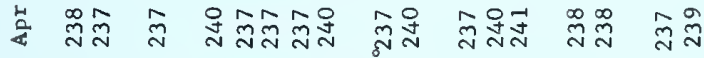

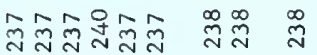

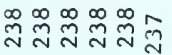

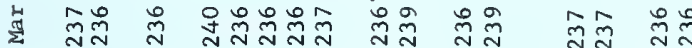

䜣

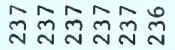

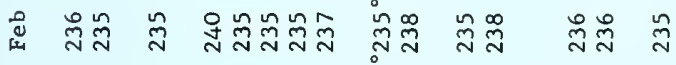

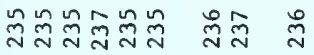

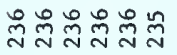

剂

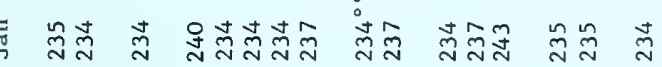

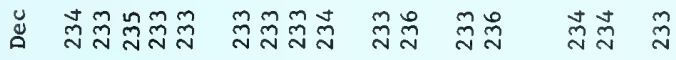

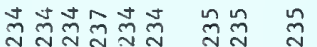

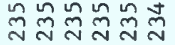

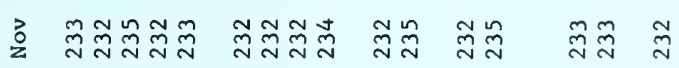

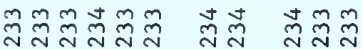

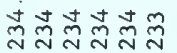

प लैचี

กีल $\tilde{ก}$

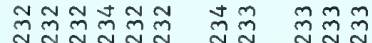

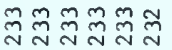

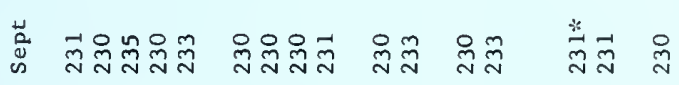

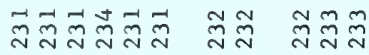

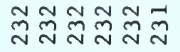

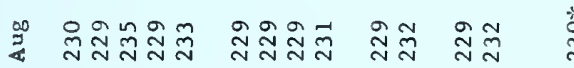

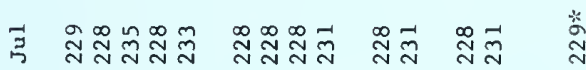

ำำ

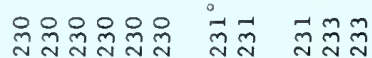

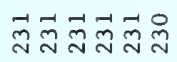

్ㅠ류류류류

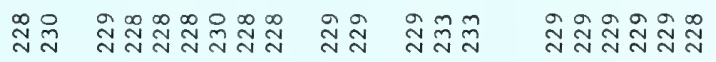

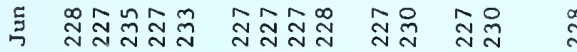

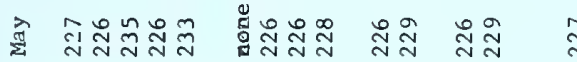

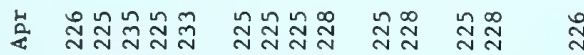

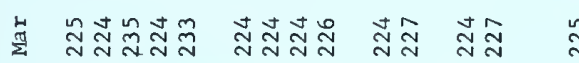

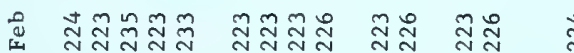

ด้|

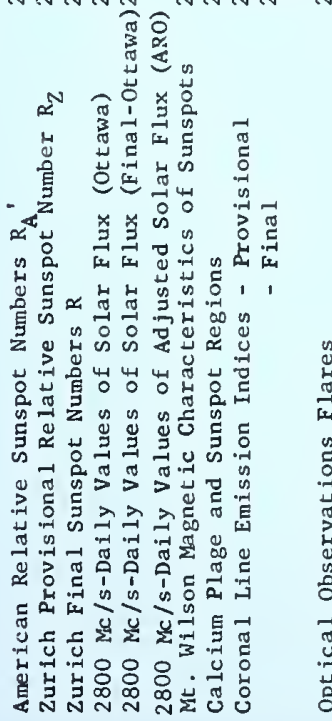

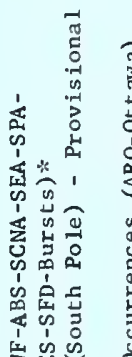

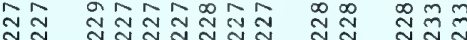

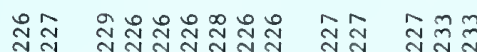

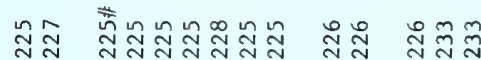

A

\section{สิ}

สะส

N

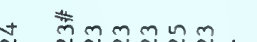

กิั

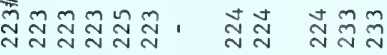

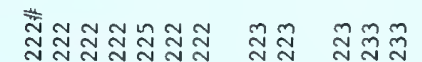

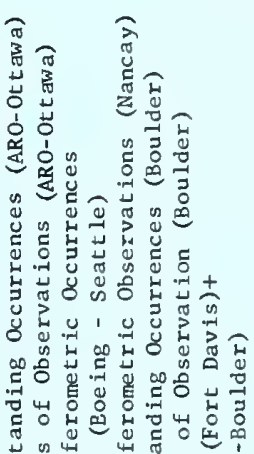

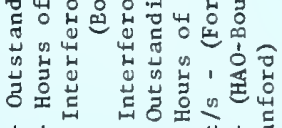

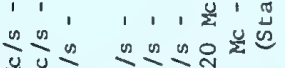

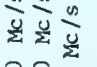

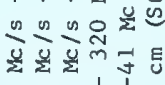

品京

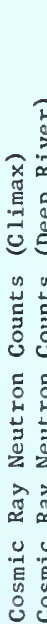

กั

$\stackrel{0}{5}$

के

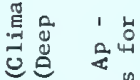

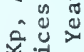

ن密总

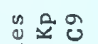

牙岁㟧

荡荡

ฮั ธิ

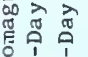

نำ

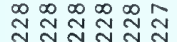

ลิกีสิกีกี้

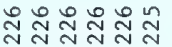

ลักิ

สิง

ลิกิกิกีกิ

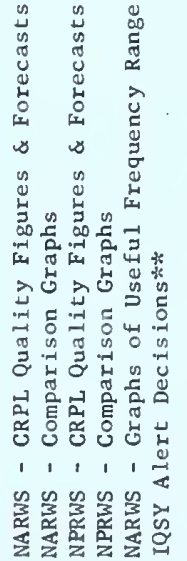





\section{International Geophysical Calendar 1965}
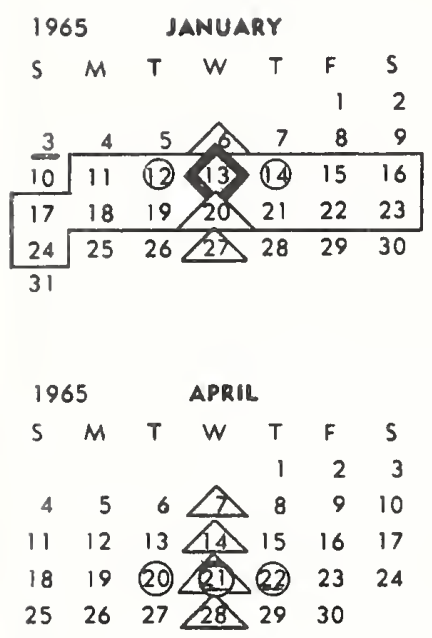
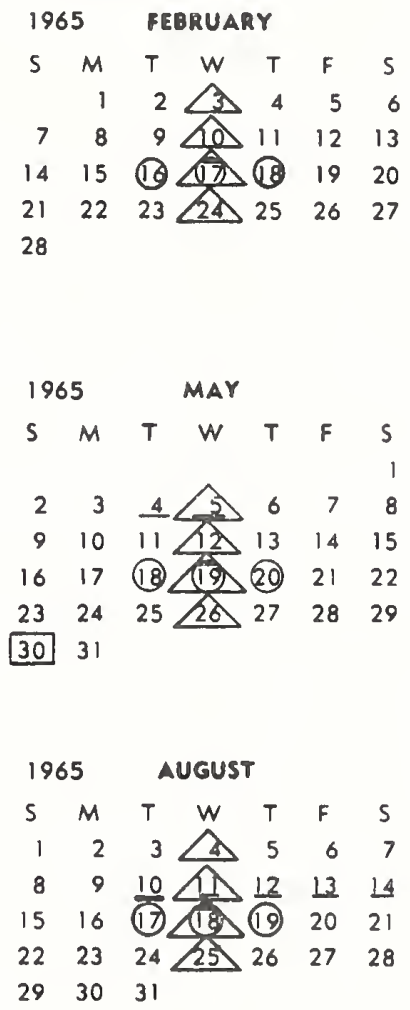

1965 NOVEMBER

$$
\begin{array}{ccccccc}
5 & M & T & W & T & F & S \\
& 1 & 2 & 3 & 4 & 5 & 6 \\
7 & 8 & 9 & 0 & 11 & 12 & 13 \\
14 & 15 & 10 & 13 & 10 & 19 & 20 \\
21 & 22 & 23 & 24 & 25 & 26 & 27 \\
28 & 29 & 30 & & &
\end{array}
$$

\section{IQSY}

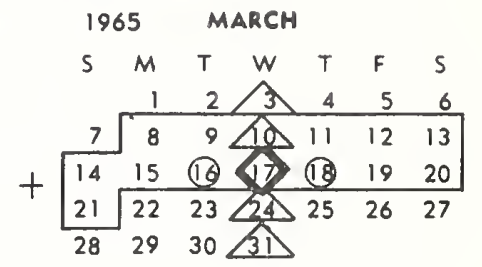

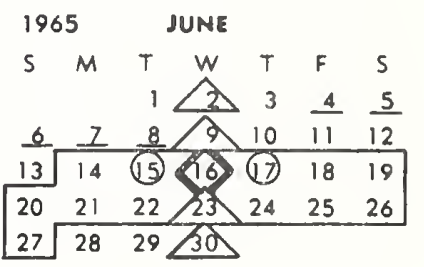

\section{SEPTEMBER}

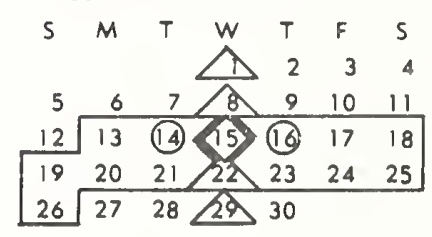

1965 DECEMBER

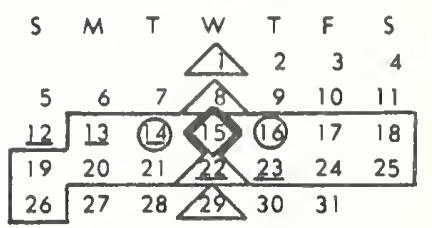

1966 JANUARY

$S M T W T$ T S

$\begin{array}{llllll}2 & 3 & 4 & & & \\ 10 & 8 & \end{array}$

$9 \quad 10$ (1) $\angle 2$ (13) $14 \quad 15$

$\begin{array}{lllll}16 & 17 \quad 18 & 19 & 21 & 22\end{array}$

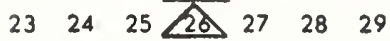

$30 \quad 31$
(17) Regular World Day (RWD)

[3] Day of Solar Eclipse
24) Quarterly Warld Day (QWD),

(18) Priority Regular Warld Day (PRWD)

7 Day with unusual metear shawer activity 15 Regular Geophysical Day (RGD)

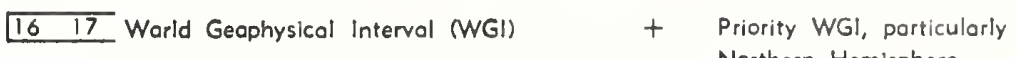
Northern Hemisphere 


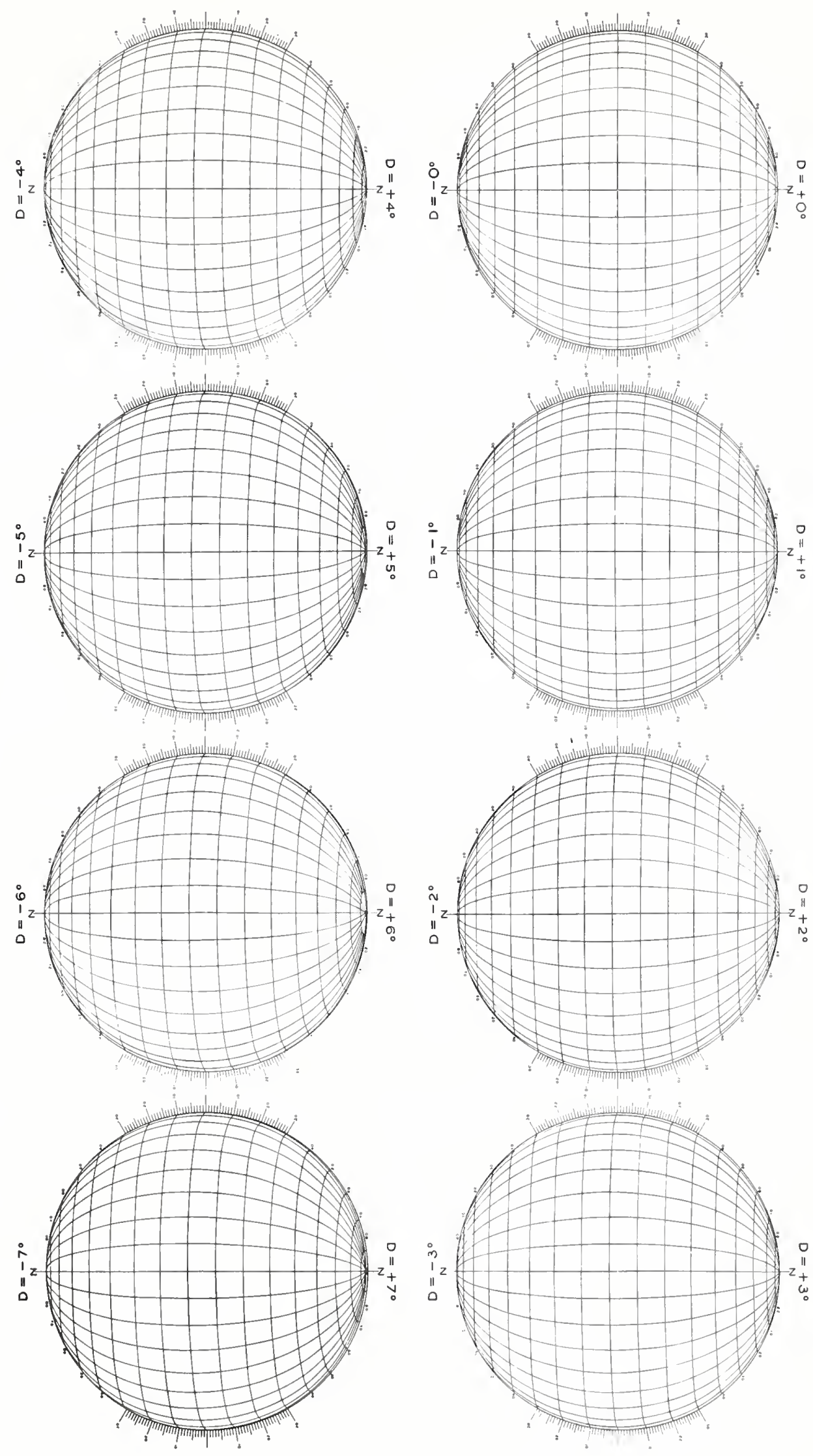


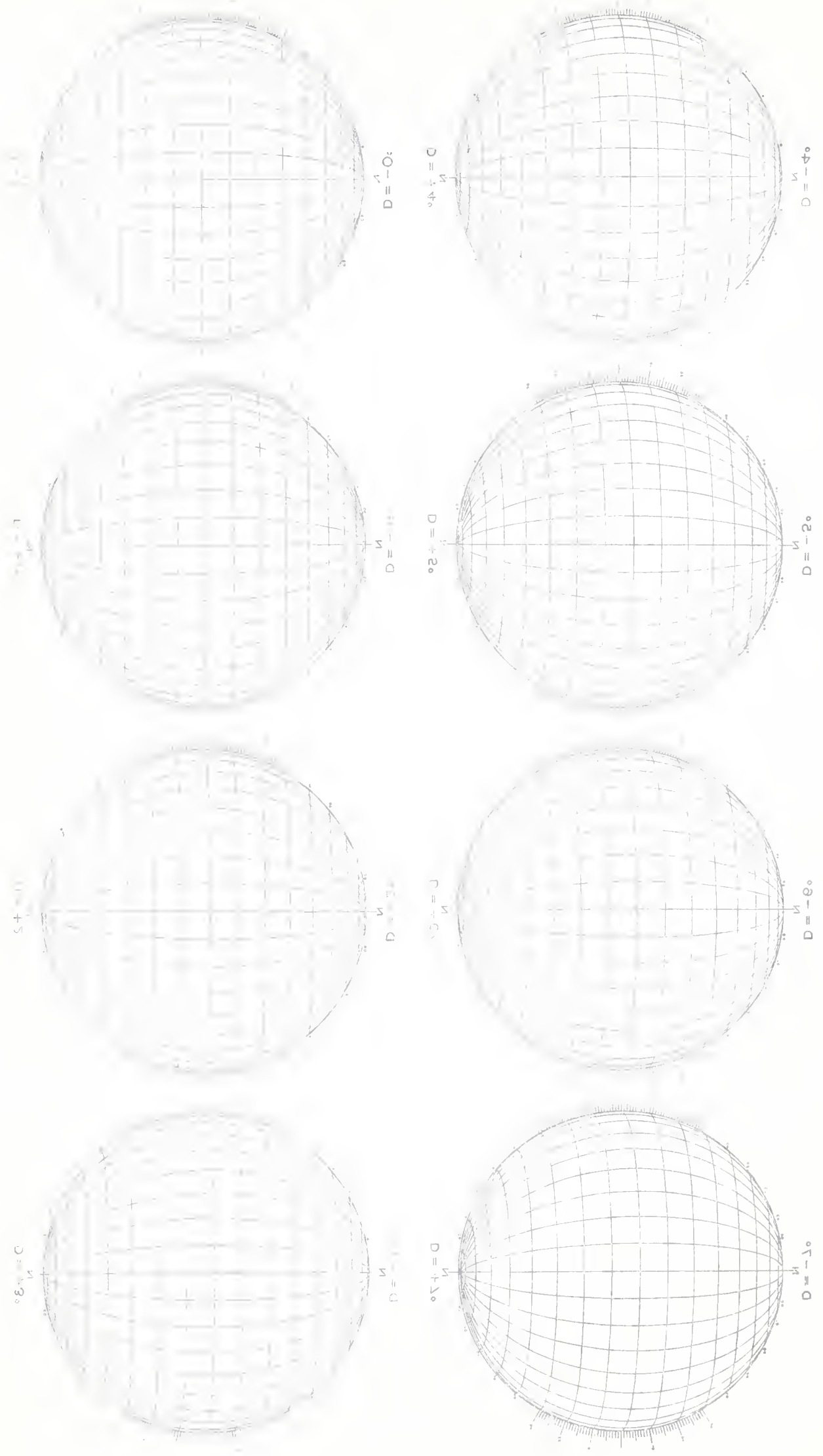





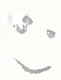

